\title{
Phenotypic and transcriptomic characterization of a wheat tall mutant carrying an induced mutation in the $\mathrm{C}$ - terminal PFYRE motif of RHT-B1b
}

Youngjun $\mathrm{Mo}^{1,3}$, Stephen Pearce ${ }^{2}$ and Jorge Dubcovsky ${ }^{1,4^{*}}$ (D)

\begin{abstract}
Background: As central regulators of the gibberellic acid (GA) signaling pathway in plants, DELLA proteins function as growth repressors and affect diverse biological processes. The wheat RHT-B1b and RHT-D1b semi-dwarfing alleles, which encode GA-insensitive DELLA proteins, have been widely adopted in modern wheat varieties to improve lodging tolerance and harvest index. However, the molecular mechanisms by which DELLA modulates these responses in wheat remain largely unknown.

Results: We identified a tall tetraploid wheat mutant line carrying an induced missense mutation (E529K) in the PFYRE motif of RHT-B1b that partially suppressed the semi-dwarf phenotype. The height-increasing effect of RHTB1 b $529 k_{\text {K relative to }}$ RHT-B1b (19 cm or $21 \%$ increase) was significantly smaller than the effect of RHT-B1a (33 cm or $34 \%$ increase) relative to RHT-B1b in the same field experiment. The RHT-B1 $\mathrm{b}_{\text {E529K }}$ mutation was also associated with length increases in coleoptiles, seedling shoots, and stem internodes relative to the RHT-B1b allele. We detected no significant differences in germination rate, seedling root length, tiller number, flag leaf size, spike length, or yield components. Using RNA-seq, we compared gene expression profiles of plants encoding RHT-B1b and RHT-B1 $\mathrm{b}_{\mathrm{E} 529 \mathrm{~K}}$ in coleoptile, first leaf, and elongating peduncles. We detected limited overlap among tissues of the genes differentially regulated by the two genotypes, and more genes upregulated (77\%) than downregulated (23\%) in RHT-B1 $b_{\text {E529K }}$ relative to RHT-B1b. These results suggest that the wheat DELLA protein affects the transcriptome in a tissue-specific manner and that the mutation mainly eliminates or reduces repression functions of the RHT-B1 protein. Our study identified distinct sets of potential DELLA direct or indirect target genes involved in cell wall and carbohydrate metabolisms, cell cycle/division, and hormone pathways.

Conclusions: We identified the hypomorphic RHT-B1 b $529 k_{k}$ allele that confers an intermediate plant height and coleoptile elongation. This allele can be useful in rain-fed wheat breeding programs where the strong reduction in height and biomass associated with RHT-B1b has detrimental effects. Transcriptomic characterization of different tissues from the plants encoding RHT-B1 $\mathrm{b}_{\mathrm{E} 529 \mathrm{~K}}$ and RHT-B1b provided valuable information for identifying DELLA downstream GA response genes in wheat.
\end{abstract}

Keywords: Wheat, Plant height, RHT1, DELLA, RNA-seq, Transcriptome

\footnotetext{
* Correspondence: jdubcovsky@ucdavis.edu

${ }^{1}$ Department of Plant Sciences, University of California, Davis, CA 95616, USA

${ }^{4}$ Howard Hughes Medical Institute, Chevy Chase, MD 20815, USA

Full list of author information is available at the end of the article
}

(c) The Author(s). 2018 Open Access This article is distributed under the terms of the Creative Commons Attribution 4.0 International License (http://creativecommons.org/licenses/by/4.0/), which permits unrestricted use, distribution, and reproduction in any medium, provided you give appropriate credit to the original author(s) and the source, provide a link to the Creative Commons license, and indicate if changes were made. The Creative Commons Public Domain Dedication waiver (http://creativecommons.org/publicdomain/zero/1.0/) applies to the data made available in this article, unless otherwise stated. 


\section{Background}

Gibberellins (GAs) are a family of plant hormones that regulate a diverse range of developmental processes including germination, leaf expansion, stem elongation, phase transition, and flowering [1]. GA biosynthesis and deactivation are highly regulated by a number of metabolic enzymes encoded by multi-gene families, and the downstream GA signaling pathway is mainly regulated by DELLA proteins $[2,3]$. Lacking a canonical DNA binding site, DELLA represses growth in the absence of GA through physical interaction with its target proteins (reviewed in [4]). Mechanisms include the sequestration of transcription factors and transcriptional regulators and the transactivation of growth repressor genes [5-10]. When bioactive GAs are perceived by the receptor protein GID1 (GIBBERELLIN INSENSITIVE DWARF1), conformational change occurs in the N-terminal region of GID1 and enhances the formation of the GA-GID1-DELLA complex [11, 12]. This enables the SCF (SKP1, CULLIN, F-box) E3 ubiquitin ligase complex to recognize and polyubiquitinate DELLA, which leads to its degradation via the $26 \mathrm{~S}$ proteasome pathway [13]. DELLA targets are then released, promoting downstream GA-mediated growth responses.

DELLA proteins belong to the GRAS (GAI, RGA, and SCR) protein family and are composed of two major domains - the N-terminal regulatory domain (DELLA, LExLE, and TVHYNP motifs) and the C-terminal functional domain (LHRI, VHIID, LHRII, PFYRE, and SAW motifs). The N-terminal, or DELLA, domain, is involved in GID1 binding and confers functional specificity that distinguishes DELLA from other members of the GRAS subfamily $[14,15]$. The C-terminal, or GRAS, domain is highly conserved among the GRAS subfamilies. The first leucine heptad repeat (LHRI) motif of the GRAS domain is essential for DELLA's interaction with its target proteins (e.g. PIF4 [5], JAZ1 [8], and AtIDD3 [16]). The LHRI-VHIIDLHRII structure is highly conserved among GRAS subfamily proteins and has been shown to play similar roles [15]. The adjacent PFYRE motif is less conserved and its specific role in protein-protein interaction is currently not clear $[4$, 15]. Finally, the distal SAW motif is crucial for the DELLA's interaction with BZR1 [7] and GAF1 [10].

In hexaploid wheat (Triticum aestivum; $2 \mathrm{n}=42$, AABBDD), the DELLA proteins are encoded by three RHT1 (REDUCED HEIGHT 1) homeologs - RHT-A1, RHT-B1, and RHT-D1 on chromosome 4AL, 4BS, and 4DS, respectively. During the 'Green Revolution' in the 1960 s, the semi-dwarfing $R h t-B 1 b$ and $R h t-D 1 b$ alleles were introduced into breeding programs to develop high-yielding wheat varieties [17]. The short and strong stem of these modern varieties greatly improved productivity by preventing lodging under high fertilizer input and enhancing the efficiency of photosynthate partitioning into grains [18-20]. Both Rht-B1b and Rht-D1b alleles have a point mutation inducing a premature stop codon in the N-terminal DELLA domain [21] that prevents GID1 binding. It has been suggested that translation reinitiates after these stop codons, to produce N-terminally truncated DELLA proteins with the active GRAS domain retaining its ability to repress growth. These truncated DELLAs cannot detect the GID1-mediated GA signals, thus conferring GA-insensitive semi-dwarfism [21].

$R h t-B 1 b$ and $R h t-D 1 b$ are the major semi-dwarfing alleles and are present in over $70 \%$ of wheat cultivars worldwide [22, 23]. Although their effects on yield are positive in optimal environments, negative pleiotropic effects such as low seedling vigor $[24,25]$ and susceptibility to Fusarium head blight $[26,27]$ have been reported. In order to improve allelic diversity, find alternative $R H T 1$ alleles, and understand better the function of the different DELLA subdomains, several natural and induced variants in the RHT1 genes have been studied previously. Additional GA-insensitive dwarfing alleles found in natural germplasm include $R h t-B 1 c$ (in-frame insertion of 30 amino acids between the DELLA and LExLE motifs $[28,29]$ ), Rht-B1e and Rht-B1p (nonsense mutations located three and four amino acids prior to the Rht-B1b mutation, respectively [30,31]), and Rht-D1c (increased copy number of Rht-D1b [29]). Also, natural polymorphic sites including insertions, deletions and point mutations have been identified in the coding and untranslated regions of all three RHT1 homeologs by sequencing [32] or ecotype targeting induced local lesions in genomes (EcoTILLING) [33]. In addition to natural variation, suppressor screens using chemically mutagenized dwarf wheat identified derivative $R h t-B 1 c$ alleles in the LHRI, VHIID, PFYRE, and SAW motifs that confer overgrowth phenotypes $[34,35]$.

In this study, we identified a mutant line exhibiting an increased height phenotype from a tetraploid wheat (Triticum turgidum; $2 \mathrm{n}=28$, AABB) TILLING population mutagenized with ethyl methanesulfonate (EMS). This line carries a missense mutation in the PFYRE motif of the RHT-B1b protein suppressing the dwarfing effect of $R h t-B 1 b$. We describe its effect on major agronomic traits and analyze transcriptomic changes induced in different tissues using RNA-seq.

\section{Results}

Mutations in the C-terminal GRAS domain of RHT-B1b partially suppress the semi-dwarfing effect of RHT-B1b A tall mutant line (T4-934) was identified in this study from an EMS-mutagenized population of the durum wheat variety Kronos developed before [36]. Because the parental variety of this population (Kronos) carries the semi-dwarfing $R h t-B 1 b$ allele, we hypothesized that the increased height of T4-934 may result from a second-site mutation in Rht-B1b suppressing the effects of this allele. We sequenced the C-terminal region of $R H T-B 1$ and 
found that T4-934 carries a G-to-A mutation at position 1,585 from the start codon (G1585A), changing a negatively charged glutamate (E, the last $\mathrm{E}$ in the PFYRE motif designation) to a positively charged lysine (K) (hereafter

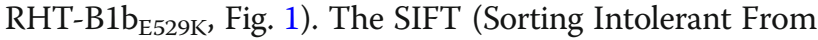
Tolerant [37]) score of the RHT-B1b $\mathrm{E}_{\mathrm{E} 29 \mathrm{~K}}$ mutation is zero, indicating that it changes a conserved amino acid residue and has a high probability of producing deleterious effects (Additional file 1: Table S1). We used the previously published exome sequencing of the complete Kronos TILLING population [38] to confirm that, except for $\mathrm{E} 529 \mathrm{~K}$, there were no additional mutations in the RHT-B1 coding sequence in T4-934.

In the $F_{2}$ and $\mathrm{BC}_{1} \mathrm{~F}_{2}$ populations from the cross between T4-934 and the non-mutagenized Kronos (recurrent parent), plants homozygous for RHT-B1 $b_{\mathrm{E} 529 \mathrm{~K}}$ were significantly taller than plants homozygous for RHT-B1b $(P<0.0001)$ when grown under field conditions, with an estimated additive effect of $10.0 \mathrm{~cm}\left(\mathrm{~F}_{2}\right)$ and $9.4 \mathrm{~cm}$ $\left(\mathrm{BC}_{1} \mathrm{~F}_{2}\right.$, Table 1). Estimated degrees of dominance [39] for the $\mathrm{F}_{2}(\mathrm{D}=0.18)$ and $\mathrm{BC}_{1} \mathrm{~F}_{2}(\mathrm{D}=0.30)$ indicated partial dominance of the height-increasing allele (Table 1).

In the same field experiment, the $\mathrm{BC}_{1} \mathrm{~F}_{2}$ population Kronos*2/T4-934 was grown together with the $\mathrm{BC}_{1} \mathrm{~F}_{2}$ population Kronos*2/Gredho, which segregated for the wild-type RHT-B1a and the semi-dwarfing RHT-B1b alleles. In the Kronos*2/T4-934 population, homozygous RHT-B1b $_{\mathrm{E} 529 \mathrm{~K}}$ plants were $19 \mathrm{~cm}$ taller (21\%) than homozygous RHT-B1b plants (Fig. 2a), whereas in the Kronos*2/Gredho population homozygous RHT-B1a plants were $33 \mathrm{~cm}$ taller (34\%) than homozygous RHT-B1b plants (Fig. 2b). A two-way factorial ANOVA including populations and RHT-B1 alleles as factors showed a highly significant interaction $(P=0.0024)$, confirming that the height difference between RHT-B1a and RHT-B1b was significantly larger than that between

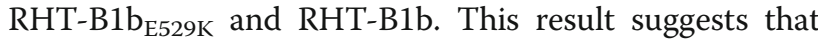
the E529K mutation is responsible for a partial suppression of the dwarfing effect of RHT-B1b.

The screening of the Kronos TILLING database [38] yielded six additional lines carrying nonsynonymous mutations in the distal part of the C-terminal GRAS domain of RHT-B1b including the SAW and part of PFYRE motifs (Fig. 1). Interestingly, one of these lines, T4-1405, carried the same E529K mutation as T4-934. Comparison of exome sequencing data in several independent genes using the TILLING database (https:// dubcovskylab.ucdavis.edu/wheat_blast) showed that E529K was the only common mutation between the two lines, confirming their independent origin. We grew $\mathrm{M}_{4}$ populations $(n=16-18)$ segregating for each non-synonymous mutation under greenhouse conditions to determine their effect on plant height. Induced mutations identified in T4-1405 (E529K) and T4-3545 $($ W605*) showed highly significant increases $(P=$ 0.0007 and $<0.0001$, respectively) in plant height compared to wild-type Kronos (Fig. 2c, d; Additional file 1: Table S1). Plants homozygous for these two mutant alleles were significantly taller $(95.6 \mathrm{~cm}$ and $97.5 \mathrm{~cm}$ for T4-1405 and T4-3545, respectively) than wild-type Kronos $(70.0 \mathrm{~cm})$, and of similar height to the homozygous RHT-B1b E529K $_{\text {plants }}(94.0 \mathrm{~cm})$. No significant effects on plant height were detected for the other four mutations (Fig. 1; Additional file 1: Table S1).

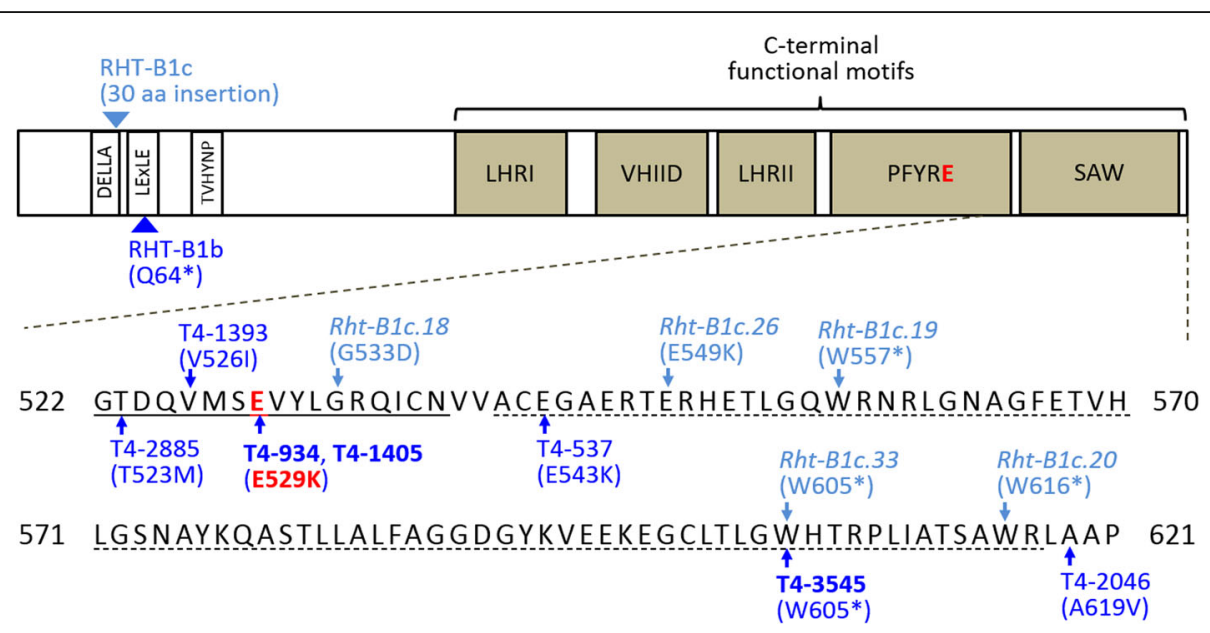

Fig. 1 Induced mutations identified in the distal region of the C-terminal domain of RHT-B1. Dark blue arrows indicate the locations of induced amino acid changes in RHT-B1b identified in this study (coordinates based on RHT-B1a, JF930278). The three mutations associated with increased height are highlighted in bold. The RHT-B1 b $529 \mathrm{~K}_{\text {}}$ mutation is highlighted in red. Light blue arrows indicate the locations of previously reported induced amino acid changes in RHT-B1C associated with increased height [34, 35]. Dark blue and light blue triangles indicate the positions of the Q64* premature stop codon in RHT-B1b and the 30 amino acid insertion in RHT-B1c, respectively. The PFYRE and SAW motifs [4] are underlined with solid and dashed lines, respectively 
Table 1 Effects of RHT-B1 $b_{\text {E529K }}$ on major agronomic traits

\begin{tabular}{|c|c|c|c|c|c|c|c|c|c|c|c|c|}
\hline \multirow[t]{2}{*}{ Trait } & \multicolumn{6}{|l|}{$F_{2}$} & \multicolumn{6}{|l|}{$\mathrm{BC}_{1} \mathrm{~F}_{2}$} \\
\hline & $\begin{array}{l}\text { Wild }^{\mathrm{a}} \\
(n=23)\end{array}$ & $\begin{array}{l}\mathrm{Het}^{\mathrm{b}} \\
(n=40)\end{array}$ & $\begin{array}{l}\text { Mut }^{\mathrm{C}} \\
(n=21)\end{array}$ & $P$ & Add $^{d}$ & $\overline{\operatorname{DoD}^{e}}$ & $\begin{array}{l}\text { Wild } \\
(n=30)\end{array}$ & $\begin{array}{l}\text { Het } \\
(n=56)\end{array}$ & $\begin{array}{l}\text { Mut } \\
(n=33)\end{array}$ & $P$ & Add & $\overline{\mathrm{DoD}}$ \\
\hline Plant height (cm) & $89.8 a$ & $101.6 \mathrm{~b}$ & $109.8 \mathrm{c}$ & $<0.0001$ & 10.0 & 0.18 & $89.6 a$ & $101.8 \mathrm{~b}$ & $108.3 c$ & $<0.0001$ & 9.4 & 0.30 \\
\hline Peduncle $(\mathrm{cm})$ & $41.9 a$ & $47.4 b$ & $50.7 \mathrm{c}$ & $<0.0001$ & 4.4 & 0.23 & $40.8 \mathrm{a}$ & $47.1 b$ & $49.1 \mathrm{C}$ & $<0.0001$ & 4.2 & 0.52 \\
\hline 2nd internode $(\mathrm{cm})$ & $17.0 \mathrm{a}$ & $19.8 b$ & $21.9 c$ & $<0.0001$ & 2.5 & 0.14 & $17.5 \mathrm{a}$ & $20.1 b$ & $21.5 c$ & $<0.0001$ & 2.0 & 0.30 \\
\hline $3 r d$ internode $(\mathrm{cm})$ & $9.1 \mathrm{a}$ & $11.0 \mathrm{~b}$ & $10.9 b$ & $<0.0001$ & 0.9 & 1.11 & $9.9 a$ & $11.8 b$ & $13.3 \mathrm{c}$ & $<0.0001$ & 1.7 & 0.12 \\
\hline 4th internode $(\mathrm{cm})$ & $6.2 \mathrm{a}$ & $7.3 b$ & $8.3 b$ & $<0.0001$ & 1.1 & 0.05 & $6.8 a$ & $8.0 b$ & $9.0 \mathrm{c}$ & $<0.0001$ & 1.1 & 0.09 \\
\hline Internode no. & 4.3 & 4.3 & 4.2 & 0.9542 & & & 4.3 & 4.3 & 4.3 & 0.6957 & & \\
\hline Tiller no. per plant & 8.0 & 7.9 & 7.6 & 0.8495 & & & 8.1 & 8.1 & 7.9 & 0.8929 & & \\
\hline Flag leaf length (cm) & 24.6 & 24.7 & 25.9 & 0.2809 & & & 24.4 & 25.2 & 25.1 & 0.4041 & & \\
\hline Flag leaf width $(\mathrm{cm})$ & 2.0 & 2.0 & 2.0 & 0.1277 & & & 2.1 & 2.1 & 2.0 & 0.2574 & & \\
\hline Days to heading & 122.2 & 121.6 & 121.2 & 0.4294 & & & 121.5 & 120.8 & 120.8 & 0.4286 & & \\
\hline Spike length $(\mathrm{cm})$ & 8.4 & 8.3 & 8.5 & 0.7560 & & & 8.5 & 8.6 & 8.6 & 0.5930 & & \\
\hline Spikelet no. per spike & 20.0 & 20.1 & 20.3 & 0.4751 & & & 20.0 & 20.1 & 20.6 & 0.0503 & & \\
\hline Grain no. per spike & 62.0 & 59.8 & 60.1 & 0.7566 & & & $59.5 a$ & $65.8 \mathrm{a}$ & $58.8 \mathrm{a}$ & 0.0672 & & \\
\hline 1,000 grain weight (g) & 53.7 & 53.9 & 53.7 & 0.9791 & & & 50.8 & 53.6 & 53.8 & 0.4874 & & \\
\hline
\end{tabular}

a, b, c Homozygous RHT-B1b, heterozygous, and homozygous RHT-B1b ${ }_{E 529 k}$ plants, respectively. ${ }^{d}$ Additive effect. ${ }^{e}$ Degree of dominance calculated as [(heterozygote value - midpoint value between the two homozygotes)/additive effect]. Significant $P$-values $(<0.05)$ from the ANOVAs are emphasized with bold letters. Trait values with different letters $(a, b$, and $c)$ indicate significant difference by Tukey's multiple comparison test at $P<0.05$

Taken together, these results demonstrate that the

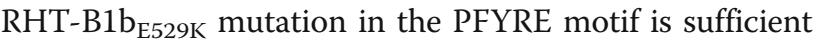
to suppress significantly (but not completely) the semi-dwarf phenotype of lines carrying the RHT-B1b allele and that the mutant RHT-B1b $\mathrm{E}_{\mathrm{E} 529 \mathrm{~K}}$ allele is partially dominant for increased plant height.

\section{Effect of RHT-B1 $b_{\mathrm{E} 529 \mathrm{~K}}$ on other agronomic traits}

In field experiments, all above-ground internodes were significantly longer $(P<0.0001)$ in homozygous RHT-B1b $\mathrm{E}_{\mathrm{E} 52 \mathrm{~K}}$ plants than in homozygous RHT-B1b plants in both the $F_{2}$ and $\mathrm{BC}_{1} \mathrm{~F}_{2}$ populations (Table 1 ; Fig. 3 ), demonstrating that RHT-B1b $\mathrm{E}_{\mathrm{E} 29 \mathrm{~K}}$ enhances stem growth throughout the elongation period. For all internodes, we found positive values for the degree of dominance, indicating partial dominance of the allele for increased length (Table 1; Fig. 3). RHT-B1b $\mathrm{E}_{\mathrm{E} 529 \mathrm{~K}}$ had no significant effect on internode number, tiller number per plant, flag leaf length and width, days to heading, spike length, spikelet and grain number per spike, and grain weight (Table 1).

We found no significant difference in germination rate between homozygous RHT-B1 $b_{\mathrm{E} 529 \mathrm{~K}}$ and RHT-B1b plants in $\mathrm{BC}_{1} \mathrm{~F}_{3}$ sister lines (Fig. 4a). However, in two-week-old seedlings, both coleoptiles and shoots were significantly lon-

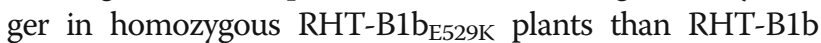
plants (Fig. 4b and c). Compared to homozygous RHT-B1b sister lines, coleoptiles and shoots of two-week-old homozygous RHT-B1 $b_{\mathrm{E} 529 \mathrm{~K}}$ plants were $17 \%(0.5 \mathrm{~cm})$ and $22 \%(3.6$ $\mathrm{cm})$ longer $(P<0.0001)$, respectively. No significant difference was observed in seedling root length (Fig. 4b).
Taken together, these data show that RHT-B1b $\mathrm{B}_{\mathrm{E} 529 \mathrm{~K}}$ enhances coleoptile, seedling shoot, and stem elongation without affecting the other agronomic traits evaluated in this study.

\section{Effect of RHT-B1b $\mathrm{E}_{\mathrm{E} 529 \mathrm{~K}}$ on GA sensitivity}

In order to determine the effect of RHT-B1b $\mathrm{E}_{\mathrm{E} 529 \mathrm{~K}}$ on GA sensitivity, we measured the response of homozygous RHT-B1 $b_{E 529 K} B_{1} F_{3}$ plants to different $G_{3}$ concentrations (Fig. 5). As controls, we included GA-insensitive wild-type Kronos carrying RHT-B1b, and two GA-sensitive lines: an EMS-induced mutant T4-3822 previously revealed to have a $1.9 \mathrm{Mb}$ deletion encompassing the whole $R H T-B 1$ gene [40], and the tall tetraploid variety Gredho carrying the RHT-B1a allele.

As expected, the GA-insensitive Kronos showed no significant changes in coleoptile length under any tested $\mathrm{GA}_{3}$ concentration, while the GA-sensitive controls T4-3822 (RHT-B1-null) and Gredho (RHT-B1a) showed significant increases in coleoptile length under $\mathrm{GA}_{3}$ concentrations of $\geq 0.1 \mu \mathrm{M}$ and $\geq 1.0 \mu \mathrm{M}$, respectively (Fig. 5). Homozygous RHT-B1 $b_{\mathrm{E} 529 \mathrm{~K}}$ lines showed significant increase in coleoptile length only under the highest $\mathrm{GA}_{3}$ concentration (10 $\mu \mathrm{M})$. The level of GA sensitivity was determined using the GA response index (GRI) as described in "Materials and Methods" (Fig. 5). GRI of homozygous RHT-B1b $\mathrm{E}_{\mathrm{E} 529 \mathrm{~K}}$ lines was slightly higher than that of wild-type Kronos, but was lower than T4-3822 and Gredho. Our results indicate that the RHT-B1 $b_{\mathrm{E} 529 \mathrm{~K}}$ mutation in the C-terminal functional domain increases seedling sensitivity to exogenous GA in 

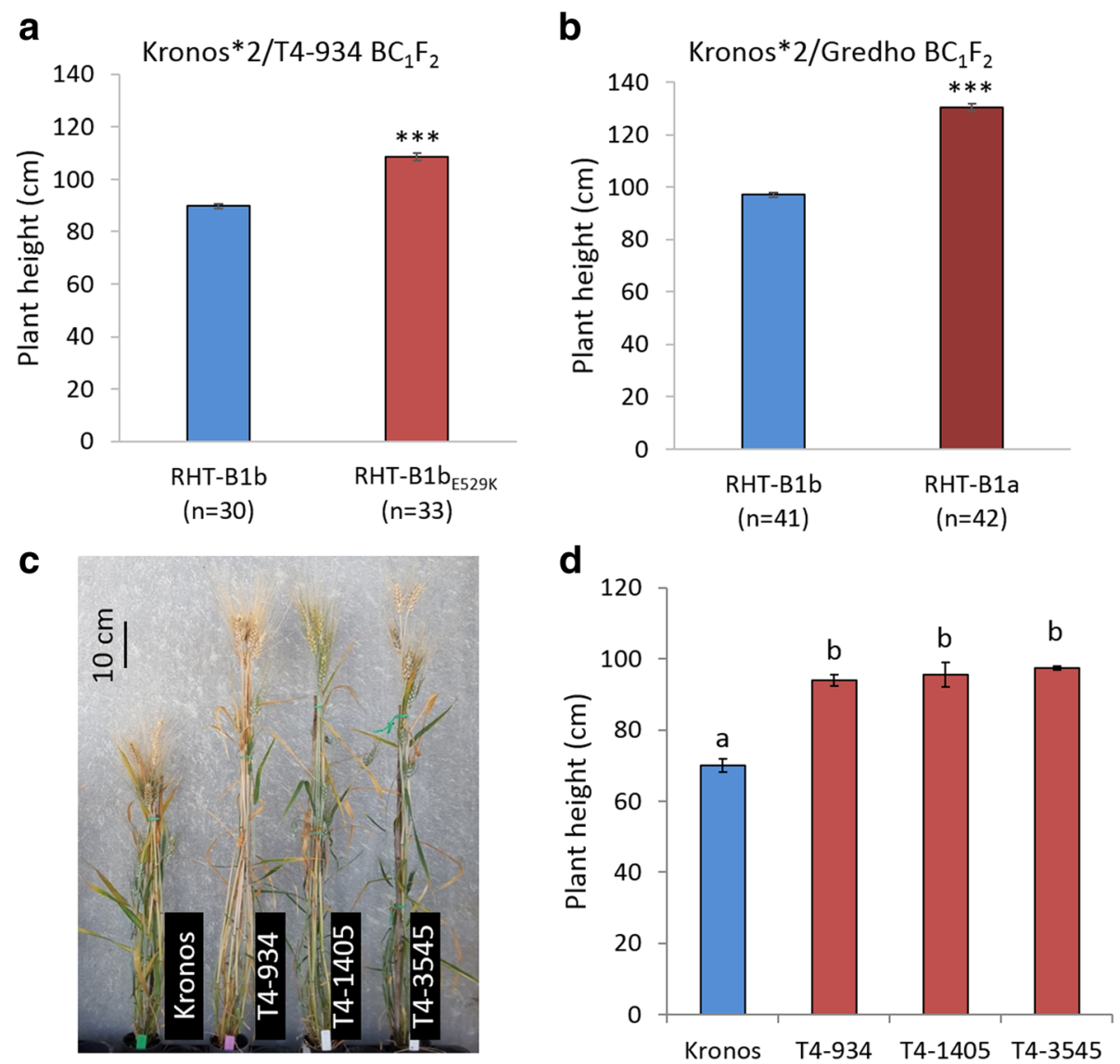

Fig. 2 Plant height of wheat plants homozygous for different RHT-B1 alleles. a Kronos*2/T4-934 plants homozygous for RHT-B1b and RHTB1 $\mathrm{b}_{\text {E529k. }}$ b Kronos*2/Gredho plants homozygous for RHT-B1b and RHT-B1a c Representative homozygous mutant lines and wild-type Kronos (see Fig. 1 for position and effect of the mutation in each line). $\mathbf{d}$ Average plant height of lines homozygous for RHT-B1 b $\mathrm{b}_{\mathrm{E} 529 \mathrm{~K}}$ (T4-1405 and T4-934) and W605* (T4-3545). Different letters (a and b) indicate significant difference in a Tukey's multiple comparison test at $P<0.05$. Error bars indicate \pm standard error of the means. $\mathbf{a}$, b Field experiments, ${ }^{* * *} P<0.0001 \mathbf{c}$, d Greenhouse experiments

spite of the presence of the Q64* stop codon mutation in the N-terminal regulatory domain of RHT-B1b (Fig. 1).

\section{Transcriptome profile comparing different tissues from

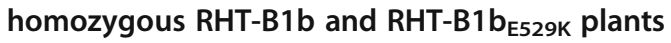

To determine the effects of RHT-B1b $\mathrm{B}_{\mathrm{E} 529 \mathrm{~K}}$ on the transcriptome, we performed an RNA-seq experiment using plant tissues that exhibited significant phenotypic differences between homozygous RHT-B1b and RHT-B1b $b_{\mathrm{E} 529 \mathrm{~K}}$ plants. In addition, these tissues are actively undergoing cell expansion, and are thus more likely to be active sites of GA signaling. We collected tissues from coleoptile, first leaf, and peduncles at early- and mid-stages (Z49 and Z52) of elongation from $\mathrm{BC}_{1} \mathrm{~F}_{3}$ sister lines homozygous for the RHT-B1b or RHT-B1 $b_{E 529 K}$ alleles. We constructed and sequenced 32 RNA-seq libraries (two genotypes $\times$ four tissues $\times$ four biological replicates), generating on average 35.9 million 100 bp single-end reads per library (Additional file 1: Table S2). For subsequent read count and differentially expressed gene (DEG) analyses, we used only reads that were uniquely mapped to a single annotated gene (IWGSC RefSeq v1.0; Additional file 1: Table S2, $70.3 \%$ of raw reads, average 25.3 million reads per library). Analysis of the reads mapping to the genomic location of the RHT-B1b $\mathrm{b}_{\mathrm{E} 529 \mathrm{~K}}$ mutation (at 30,862,966 bp on chromosome 4B; IWGSC RefSeq v1.0) confirmed the expected genotype of each RNA-seq library.

In both RHT-B1b and RHT-B1b $\mathrm{E}_{\mathrm{E} 529 \mathrm{~K}}$ genotypes, coleoptile tissue expressed the highest number of genes (70,912 and 69,688, respectively) followed by Z52 peduncle $(68,127$ and 68,208$)$, Z49 peduncle $(64,553$ and 64,373), and first leaf $(63,260$ and 64,003). A heat-map clustering analysis using the expression data of all 32 samples showed clear separation among the four different tissues, which indicated consistent differences in the transcriptome profiles among the samples from different tissues (Fig. 6a). As expected, Z49 and Z52 peduncle samples clustered more closely together than other 
a

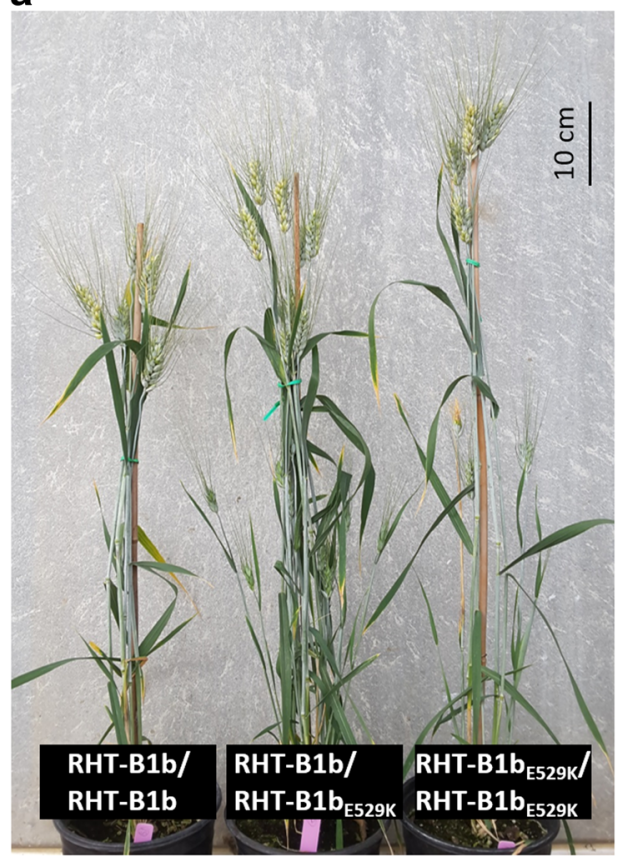

b

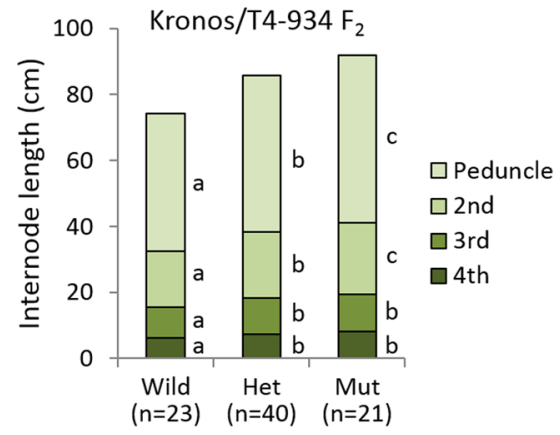

C

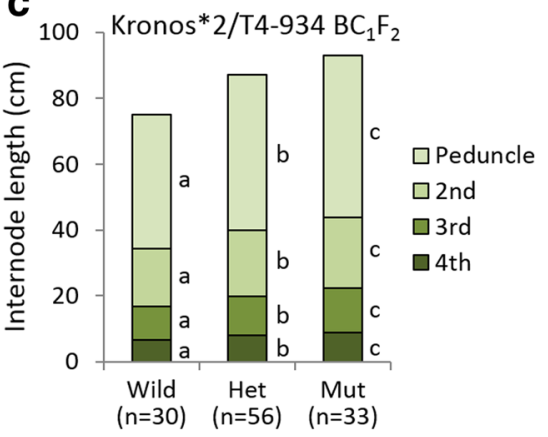

Fig. 3 Effects of RHT-B1 $b_{E 529 K}$ on stem elongation. a Representative $B C_{1} F_{3}$ plants carrying homozygous RHT-B1b, heterozygous, and homozygous RHT-B1 $b_{\text {E529K }}$ alleles. b, $\mathbf{c}$ Internodes length of homozygous RHT-B1b (Wild), heterozygous (Het), and homozygous RHT-B1 b $529 K_{2}$ plants (Mut) in $F_{2}$ and $\mathrm{BC}_{1} \mathrm{~F}_{2}$ populations, respectively. Different letters $(\mathrm{a}, \mathrm{b}$, and $\mathrm{c}$ ) indicate significant differences in a Tukey's multiple comparison test at $P<0.05$
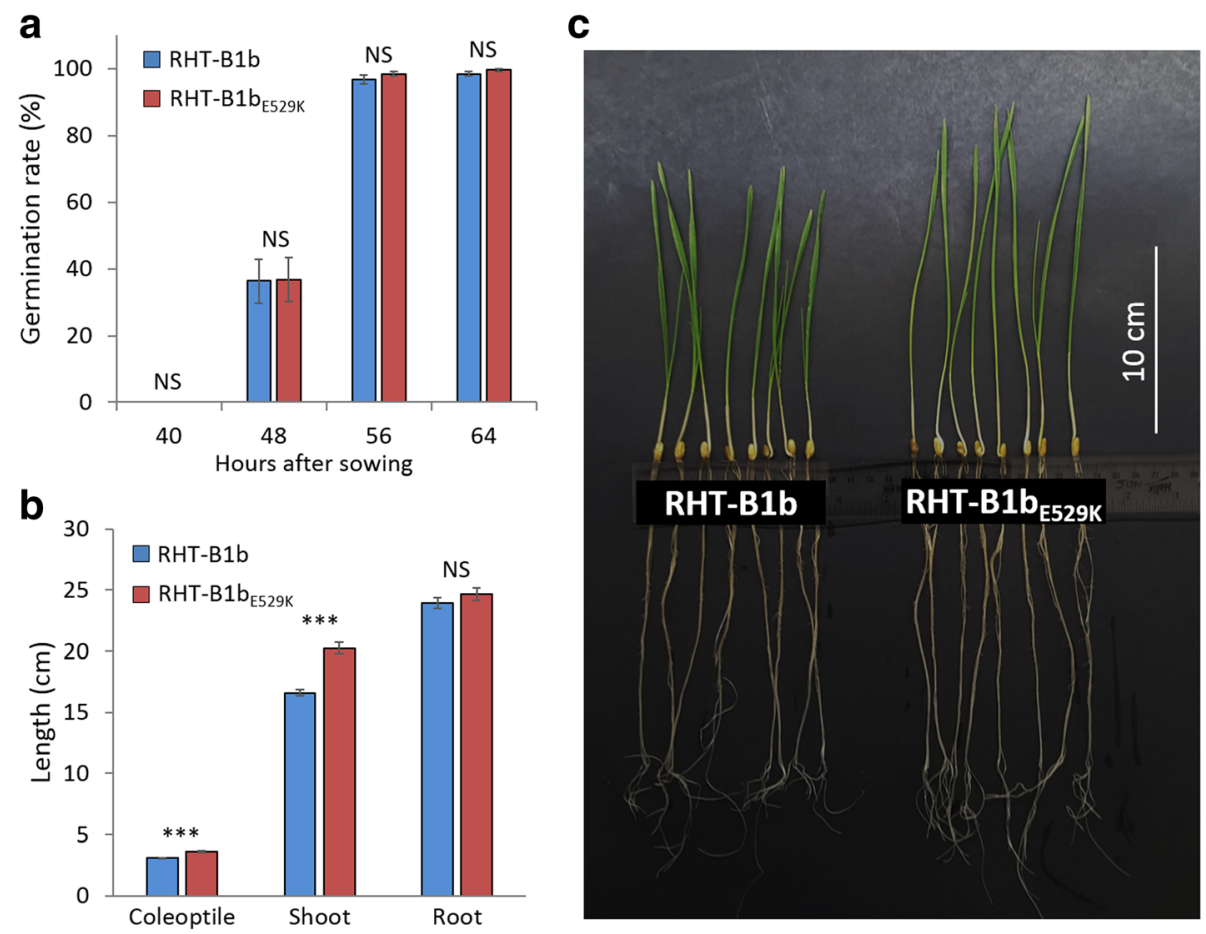

Fig. 4 Effects of RHT-B1 $b_{E 529 K}$ on germination and seedling growth. a Germination rate. $\mathbf{b}$ Coleoptile, shoot and root length measured 2 weeks after sowing. NS: not significant. **: $P<0.0001$. Error bars indicate \pm 1 standard error. c Two-week-old seedlings of homozygous RHT-B1b and $\mathrm{RHT}-\mathrm{B} 1 \mathrm{~b}_{\mathrm{E} 529 \mathrm{~K}} \mathrm{BC}_{1} \mathrm{~F}_{3}$ sister lines 


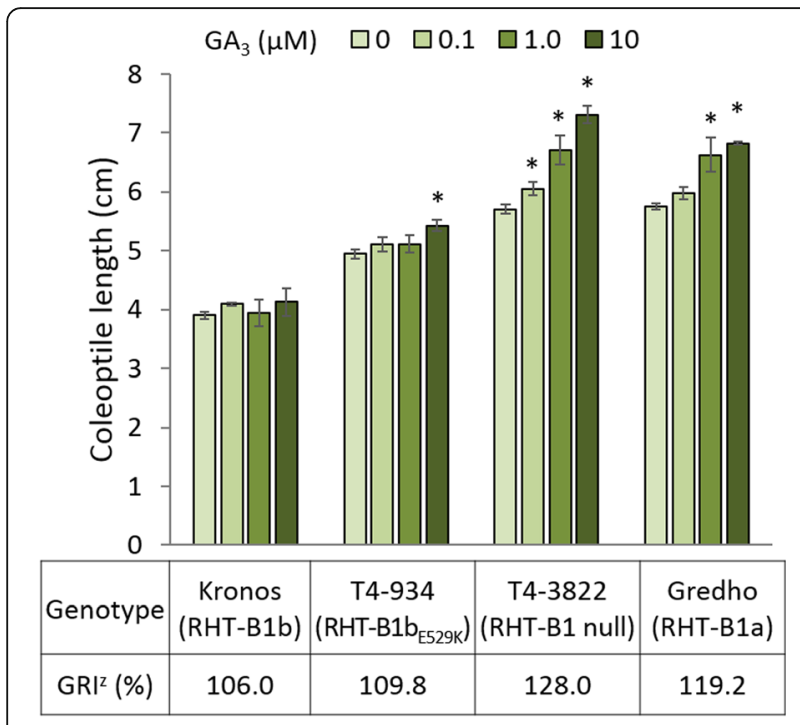

Fig. 5 Effects of RHT-B1 $b_{E 529 k}$ on GA sensitivity. An asterisk (*) indicates a significant $(P<0.05)$ difference in comparison with the control $\left(\mathrm{GA}_{3} 0 \mu \mathrm{M}\right)$ in a Dunnett's test. The GA response index (GRI) was calculated by $\left[100 \times\right.$ (length at $\mathrm{GA}_{3} 10 \mu \mathrm{M}$ )/(length at $\mathrm{GA}_{3} 0$ $\mu \mathrm{M})]$. Error bars indicate \pm 1 standard error

samples. Within each tissue, however, there was no clear separation by genotype. A similar pattern was observed in a principal component analysis (Fig. 6b), where the four tissues were separated into distinct clusters while plants encoding RHT-B1b and RHT-B1b E529K $_{2}$ clustered closely together within each tissue. These results indicated that large transcriptomic differences exist between different tissues, while a relatively smaller number of genes are differentially expressed between plants carrying the different RHT-B1 alleles.
Differentially expressed genes between plants encoding RHT-B1b and RHT-B1 $b_{\text {E529K }}$

We compared homozygous RHT-B1b and RHT-B1 $\mathrm{b}_{\mathrm{E} 529 \mathrm{~K}}$ plants to identify DEGs between genotypes in each of the four tissues. We conducted two different statistical analyses using the DESeq2 and EdgeR packages and considered a gene as differentially expressed only when they were significant (FDR-adj $P<0.05$ ) in both tests (Fig. 7a; Additional file 1: Table S3 and S4; Additional file 2: Figure S1). A small number of DEGs $(n=229)$ were identified between the homozygous RHT-B1b and RHT-B1b $\mathrm{b}_{\mathrm{E} 29 \mathrm{~K}}$ plants for the four tissues. As a comparison, nearly 120 times more DEGs $(n=27,362)$ were detected between Z49 and Z52 peduncles (6 days difference) using the same statistical criteria. No significant difference was detected in the expression of RHT-B1 between homozygous RHT-B1b and RHT-B1b $\mathrm{E}_{\mathrm{E} 529 \mathrm{~K}}$ plants (Additional file 2: Figure S2), indicating that the RHT-B1b $\mathrm{E}_{\mathrm{E} 529 \mathrm{~K}}$ mutation does not affect $R H T-B 1$ transcript levels.

Among the 229 DEGs identified between homozygous

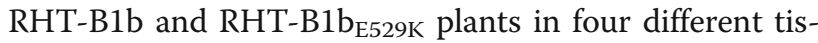
sues (Fig. 7a), the majority $(76.9 \%)$ were upregulated in the plants homozygous for the RHT-B1b $\mathrm{b}_{\mathrm{E} 529 \mathrm{~K}}$ allele. Only one gene (TraesCS3A01G407200 encoding a putative $\mathrm{NAD}(\mathrm{P}) \mathrm{H}$-quinone oxidoreductase subunit $\mathrm{N})$ was differentially expressed in two different tissues, suggesting that distinct sets of genes are regulated by DELLA in a tissue-specific manner. The full list of 229 DEGs is provided in Additional file 1: Table S3. Table 2 presents 81 selected DEGs for which we found more detailed functional information in the literature, which are described below by tissue.

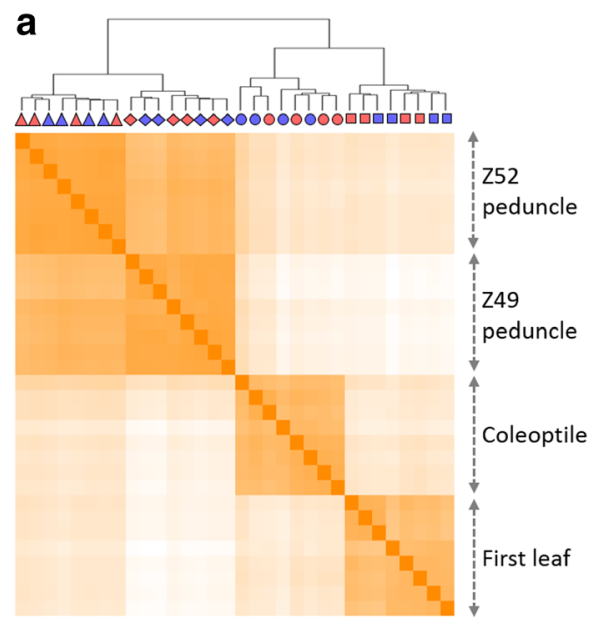

b

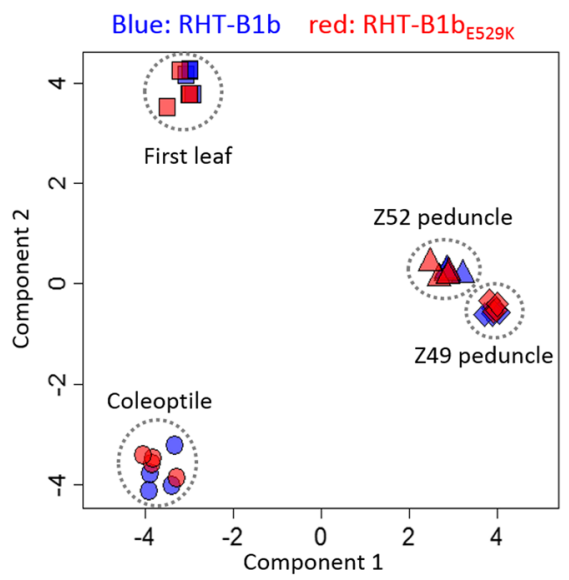

Fig. 6 Relationships among transcriptomes from four different tissues from homozygous RHT-B1b and RHT-B1 $\mathrm{b}_{\mathrm{E} 529 \mathrm{~K}}$ plants. a Hierarchical clustering of the 32 RNA-seq samples (two genotypes $\times$ four tissues $\times$ four biological replicates). b Principal component analysis of the 32 RNAseq samples. RHT-B1b and RHT-B1 $\mathrm{b}_{\mathrm{E} 529 \mathrm{~K}}$ are indicated in blue and red, respectively. Tissues are indicated by shape (circle $=$ coleoptile, square $=$ first leaf, diamond $=$ Z49 peduncle and triangle $=$ Z52 peduncle) 

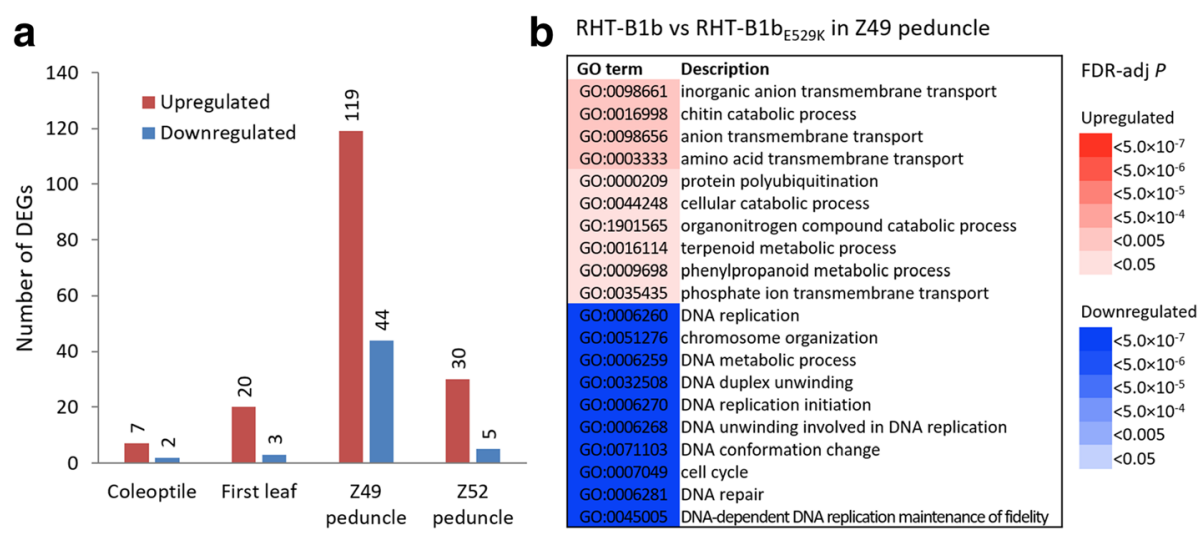

Fig. 7 Differentially expressed genes (DEGs) and gene ontology (GO) enrichment analysis. a Number of DEGs between homozygous RHT-B1b (WT) and RHT-B1 $b_{E 529 K}$ (MT) plants in four tissues. b Significantly enriched GO terms among the DEGs between plants encoding RHT-B1b and RHT-B1 $b_{E 529 K}$ in Z49 peduncle. All GO terms are from the "Biological Process" category. Upregulated and downregulated GO terms are indicated in red and blue, respectively, with gradients indicating different levels of significance. The full list of 229 DEGs is provided in Additional file 1: Table S3

\section{Coleoptile}

The seven upregulated DEGs included two genes encoding putative fatty acyl-coenzyme A reductases (FARs) that may play a role in synthesizing cell wall components [41, 42] (Table 2). A gene encoding plant defense related Hessian fly responsive-2 (Hfr-2)-like protein [43] was also upregulated. The two downregulated DEGs were a gene encoding a putative lateral organ boundaries (LOB) domain protein, a plant-specific transcription factor that regulates diverse developmental events [44], and a gene encoding a putative methionine aminopeptidase required for normal plant development [45].

\section{First leaf}

Among 23 DEGs identified in the first leaf, 20 were upregulated and three were downregulated in the homozygous RHT-B1b $\mathrm{E}_{229 \mathrm{~K}}$ plants (Fig. 7a). Similar to the coleoptile, upregulated DEGs in the mutant plants included putative defense related genes encoding NBS-LRR proteins [46], a disease resistant protein RMP1 [47], and heavy metal transport/detoxification proteins [48] (Table 2). Many genes encoding kinase proteins were also upregulated, including receptor kinase genes potentially controlling plant development and defense mechanisms [49]. Downregulated DEGs in the mutant plants included a gene encoding a UDP-glycosyltransferase potentially involved in glycosylation of plant hormones [50, 51], and a gene encoding an IAA-amino acid hydrolase likely involved in auxin regulation [52].

\section{Z49 peduncle (early-stage elongation)}

For the 119 upregulated and 44 downregulated DEGs identified in Z49 peduncle of the homozygous RHT-B1b $\mathrm{E}_{\mathrm{E} 52 \mathrm{~K}}$ plants (Fig. 7a), we first conducted a GO enrichment analysis within the "Biological Process" terms to classify the DEGs (Fig. 7b). Enriched GO terms among upregulated
DEGs were mainly associated with transmembrane transport and catabolic processes (Fig. 7b). DEGs associated with transmembrane transport included genes encoding a phosphate transporter, a sulfate transporter, two amino acid permeases, and a putative $\mathrm{Na}^{+} / \mathrm{H}^{+}$antiporter (Table 2). DEGs associated with catabolic processes included genes encoding three putative RING/U-box proteins, a carboxypeptidase, two chitinase-like proteins, and a carotenoid cleavage dioxygenase. Five additional genes encoding putative arabinogalactan proteins (AGPs), which play important roles in cell expansion and stem elongation [53-55], were also upregulated. Two genes involved in the auxin pathway (i.e., an auxin influx transporter and an auxin-responsive protein) and two genes encoding LOB domain-containing proteins were upregulated. Downregulated DEGs in the homozygous RHT-B1b $b_{\mathrm{E} 529 \mathrm{~K}}$ plants were largely enriched in GO terms associated with cell division/cycle such as DNA replication, DNA unwinding, DNA repair, and chromosome organization (Fig. 7b). DEGs related to these GO terms included genes encoding putative helicases, DNA polymerases, DNA mismatch repair proteins, histone modifiers, and cyclin proteins (Table 2). Among the downregulated genes was one encoding a GRF1-interacting factor (GIF)-like protein, which is known to promote cell proliferation [56].

\section{Z52 peduncle (mid-stage elongation)}

Among 35 DEGs identified in Z52 peduncle, 30 were upregulated and five were downregulated in the

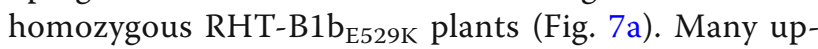
regulated DEGs were involved in carbohydrate metabolism, i.e., genes encoding three carbonic anhydrases (CAs) [57], two fructose-bisphosphate aldolases (FBAs) [58], a sucrose-phosphate synthase (SPS) [59], a glyceraldehyde-3-phosphage dehydrogenase (GAPDH) [60], a pyrophosphate:fructose 6-phosphate 1-phosphotransferase (PFP) [61], and a dihydrolipoyl dehydrogenase [62] (Table 2). 
Table 2 Selected genes differentially expressed between RHT-B1b and RHT-B1 b $\mathrm{b}_{\mathrm{E} 22 \mathrm{~K}}$

\begin{tabular}{|c|c|c|c|c|}
\hline \multirow[t]{2}{*}{ Gene ID } & \multirow[t]{2}{*}{ Description (No. of homeologs/paralogs) ${ }^{a}$} & \multicolumn{2}{|c|}{ Ave. norm. count ${ }^{b}$} & \multirow[t]{2}{*}{ FC } \\
\hline & & WT & MT & \\
\hline \multicolumn{5}{|l|}{ Coleoptile } \\
\hline TraesCS5A01G363200 & Fatty acyl-CoA reductase (2) & 67 & 856 & 12.8 \\
\hline TraesCS2B01G047200 & Hfr-2-like protein & 70 & 347 & 5.0 \\
\hline TraesCS7B01G171400 & Methionine aminopeptidase & 19 & 2 & -9.7 \\
\hline TraesCS4A01G415400 & LOB domain-containing protein, putative & 61 & 2 & -30.0 \\
\hline \multicolumn{5}{|l|}{ First leaf } \\
\hline TraesCS2B01G043600 & NBS-LRR-like resistance protein (2) & 21 & 115 & 5.4 \\
\hline TraesCS7A01G463900 & Disease resistance protein RPM1 & 45 & 188 & 4.1 \\
\hline TraesCS2B01G569100 & Heavy metal transport/detoxification superfamily protein (2) & 16 & 74 & 4.6 \\
\hline TraesCS2A01G574800 & Receptor kinase-like protein (3) & 2 & 26 & 11.2 \\
\hline TraesCS7A01G012100 & Leucine-rich repeat receptor-like protein kinase family protein & 2 & 20 & 8.9 \\
\hline TraesCS4B01G092200 & Protein kinase family protein (2) & 24 & 107 & 4.5 \\
\hline TraesCS3A01G438800 & Dual specificity mitogen-activated protein kinase kinase 4 & 110 & 330 & 3.0 \\
\hline TraesCS7A01G419700 & UDP-glycosyltransferase & 95 & 12 & -7.7 \\
\hline TraesCS2B01G091200 & IAA-amino acid hydrolase ILR1 & 10 & 1 & -13.4 \\
\hline \multicolumn{5}{|l|}{ Z49 peduncle } \\
\hline TraesCS6A01G380000 & Phosphate transporter PHO1-like protein & 53 & 117 & 2.2 \\
\hline TraesCS7A01G088700 & Sulfate transporter & 115 & 224 & 1.9 \\
\hline TraesCS3A01G388000 & Amino acid permease (2) & 46 & 108 & 2.3 \\
\hline TraesCS1A01G142400 & $\mathrm{Na}(+) / \mathrm{H}(+)$ antiporter $\mathrm{NhaB}$ & 303 & 443 & 1.5 \\
\hline TraesCS1A01G029800 & RING/U-box superfamily protein (3) & 167 & 251 & 1.5 \\
\hline TraesCS7A01G024600 & RING finger protein & 171 & 285 & 1.7 \\
\hline TraesCS2A01G205400 & U-box domain-containing protein & 465 & 764 & 1.6 \\
\hline TraesCS1B01G184500 & Carboxypeptidase & 133 & 256 & 1.9 \\
\hline TraesCS5A01G272400 & Chitinase-like protein (2) & 582 & 856 & 1.5 \\
\hline TraesCS3B01G308000 & Carotenoid cleavage dioxygenase & 577 & 1041 & 1.8 \\
\hline TraesCS3B01G773500LC & Arabinogalactan peptide 3 & 712 & 1567 & 2.2 \\
\hline TraesCS3B01G347300 & Arabinogalactan peptide 14 (3) & 62 & 140 & 2.3 \\
\hline TraesCS1A01G396700 & Fasciclin-like arabinogalactan protein & 353 & 513 & 1.5 \\
\hline TraesCS3B01G401000 & Auxin influx transporter & 1972 & 2851 & 1.4 \\
\hline TraesCS3A01G121300 & Auxin-responsive protein & 176 & 273 & 1.6 \\
\hline TraesCS2B01G289800 & LOB domain-containing protein (2) & 719 & 1060 & 1.5 \\
\hline TraesCS1A01G264000 & DNA helicase (5) & 5982 & 4213 & -1.4 \\
\hline TraesCS2A01G103300 & ATP-dependent RNA helicase DeaD (3) & 366 & 254 & -1.4 \\
\hline TraesCS4B01G124700LC & DNA polymerase & 898 & 622 & -1.4 \\
\hline TraesCS3B01G137500 & DNA polymerase epsilon subunit & 342 & 231 & -1.5 \\
\hline TraesCS3A01G117500 & DNA mismatch repair protein mutS & 242 & 162 & -1.5 \\
\hline TraesCS7A01G140800 & DNA mismatch repair protein MutL & 314 & 216 & -1.5 \\
\hline TraesCS1A01G409600 & Topoisomerase 1-associated factor 1 & 610 & 428 & -1.4 \\
\hline TraesCS4B01G045000 & Homologous-pairing protein 2-like protein & 206 & 132 & -1.6 \\
\hline TraesCS5B01G303500 & Sister chromatid cohesion 1 protein 3 & 194 & 131 & -1.5 \\
\hline TraesCS1B01G376100 & Histone H4 & 234 & 158 & -1.5 \\
\hline TraesCS5B01G186000 & Histone acetyltransferase type B catalytic subunit & 684 & 480 & -1.4 \\
\hline
\end{tabular}


Table 2 Selected genes differentially expressed between RHT-B1b and RHT-B1 $\mathrm{b}_{\mathrm{E} 529 \mathrm{~K}}$ (Continued)

\begin{tabular}{|c|c|c|c|c|}
\hline \multirow[t]{2}{*}{ Gene ID } & \multirow[t]{2}{*}{ Description (No. of homeologs/paralogs) ${ }^{a}$} & \multicolumn{2}{|c|}{ Ave. norm. count ${ }^{b}$} & \multirow[t]{2}{*}{ FC } \\
\hline & & WT & MT & \\
\hline TraesCS5A01G158800 & Histone-lysine N-methyltransferase & 238 & 148 & -1.6 \\
\hline TraesCS7B01G302500 & Non-structural maintenance of chromosome element 4 & 100 & 53 & -1.9 \\
\hline TraesCS4A01G234600 & Cyclin family protein (2) & 327 & 210 & -1.6 \\
\hline TraesCS4A01G250600 & GRF1-interacting factor-like protein & 302 & 148 & -2.0 \\
\hline \multicolumn{5}{|l|}{ Z52 peduncle } \\
\hline TraesCS3A01G230000 & Carbonic anhydrase (3) & 7582 & 13625 & 1.8 \\
\hline TraesCS7A01G381100 & Fructose-bisphosphate aldolase (2) & 1567 & 2687 & 1.7 \\
\hline TraesCS4A01G225100 & Sucrose-phosphate synthase & 236 & 556 & 2.4 \\
\hline TraesCS2B01G048200 & Glyceraldehyde-3-phosphate dehydrogenase & 372 & 575 & 1.5 \\
\hline TraesCS7B01G193600 & Pyrophosphate--fructose 6-phosphate 1-phosphotransferase subunit alpha & 234 & 385 & 1.6 \\
\hline TraesCS1B01G084700 & Dihydrolipoyl dehydrogenase & 593 & 936 & 1.6 \\
\hline TraesCS2A01G396300 & Protein SPIRAL1 (2) & 47 & 119 & 2.5 \\
\hline TraesCS7A01G405600 & Eukaryotic aspartyl protease family protein & 39 & 119 & 3.0 \\
\hline TraesCS7A01G111700LC & Chitinase & 20 & 52 & 2.6 \\
\hline TraesCS7A01G789200LC & NBS-LRR disease resistance protein-like protein & 30 & 74 & 2.5 \\
\hline TraesCS2B01G066000 & 2-oxoglutarate (2OG) and Fe(II)-dependent oxygenase superfamily protein & 696 & 467 & -1.5 \\
\hline TraesCS1A01G266000 & Phospholipase A1 & 201 & 93 & -2.2 \\
\hline TraesCS1A01G265500 & Wound-induced protease inhibitor & 38 & 4 & -9.3 \\
\hline
\end{tabular}

${ }^{a}$ Number of homeologs or paralogs DEGs with identical gene description is indicated in parenthesis.

${ }^{\mathrm{b}}$ Average normalized count from DESeq2

Other upregulated DEGs in the homozygous mutant plants included two genes encoding SPIRAL1 proteins that potentially control anisotropic cell expansion [63]. Several genes associated with defense mechanisms were also upregulated, including genes encoding an aspartyl protease [64, 65], a chitinase [66], and an NBS-LRR protein [46]. Downregulated DEGs included a gene encoding phospholipase 1, which catalyzes the initial step in jasmonic acid (JA) biosynthesis [67], and genes encoding defense-related protein such as a putative 2-oxoglutarate $\mathrm{Fe}$ (II) oxygenase [68] and a wound-induced protease inhibitor.

\section{Discussion}

\section{$\mathrm{RHT}-\mathrm{B} 1 \mathrm{~b}_{\mathrm{E} 529 \mathrm{~K}}$ as an intermediate dwarfing resource}

In addition to its strong effect on plant height, the introgression of the RHT-B1b allele into wheat germplasm has been associated with reductions in coleoptile length and seedling vigor, increased grain number per spike, and decreased grain weight relative to RHT-B1a [18, 19, 24, 69]. Our study shows that the RHT-B1b $\mathrm{B}_{\mathrm{E} 529 \mathrm{~K}}$ mutation partially suppressed the dwarfing effect of RHT-B1b. The comparison of two $\mathrm{BC}_{1} \mathrm{~F}_{2}$ backcross populations developed using the same Kronos recurrent parent and grown in the same field experiment, showed that homozygous RHT-B1b $b_{\mathrm{E} 529 \mathrm{~K}}$ plants were significantly taller than the homozygous RHT-B1b plants (21\%), but that the effect was smaller than the height increase associated with
RHT-B1a relative to RHT-B1b plants $(34 \%)$ in the other population (Fig. 2a, b).

In addition, the effect of RHT-B1b $\mathrm{b}_{\mathrm{E} 529 \mathrm{~K}}$ was also smaller than the $49 \%$ height increase observed in Kronos mutant line T4-3822 $(81.4 \mathrm{~cm}$ to $120.9 \mathrm{~cm})$, which carries a deletion encompassing the complete $R h t-B 1 b$ gene (RHT-B1-null) [40]. Although these two Kronos mutant lines were not grown in the same field experiments, the length of their coleoptiles at different GA concentrations were compared here in the same assay (Fig. 5). Coleoptiles were significantly shorter in homozygous RHT-B1b $\mathrm{B}_{\mathrm{E} 529 \mathrm{~K}}$ than in homozygous RHT-B1-null plants, both in the absence and presence of $\mathrm{GA}_{3}$. The mutation in RHT-B1b prevents its degradation by $\mathrm{GA}$, resulting in a constitutively active repressor. The $\mathrm{RHT}-\mathrm{B} 1 \mathrm{~b}_{\mathrm{E} 529 \mathrm{~K}}$ mutation likely reduces but does not completely suppress, the repression ability of $\mathrm{RHT}-\mathrm{B} 1 \mathrm{~b}$ resulting in a residual dwarfing ability.

In addition to its effect on final plant height, RHT-B1b $b_{\mathrm{E} 529 \mathrm{~K}}$ also increased the lengths of coleoptiles (17\%) and seedling shoots (22\%) relative to sister lines encoding the RHT-B1b allele (Table 1; Fig. 4). Therefore, RHT-B1 $b_{\mathrm{E} 529 \mathrm{~K}}$ might be useful as an alternative dwarfing source in rainfed environments, where taller semi-dwarf plants frequently perform better than shorter plants [70-72]. We have initiated the transfer 
of RHT-B1b $\mathrm{b}_{\mathrm{E} 529 \mathrm{~K}}$ to hexaploid common wheat to test this hypothesis.

Although variation in DELLA can affect seed germination [4], the GA-insensitive gai-1 mutant in Arabidopsis showed no differences in germination [10]. This result is consistent with previous reports on the effect of RHT-B1b suppressing stem elongation without affecting germination rate [73, 74], and with the results presented here. In addition, the RHT-B1b $\mathrm{E}_{\mathrm{E} 529 \mathrm{~K}}$ mutation did not significantly affect seedling root length, tiller number, heading time, flag leaf size, spike length, spikelet number per spike, grain number per spike, and grain weight. These results are also consistent with previous reports on the effect of RHT-B1b suppressing stem elongation without affecting seedling root growth [75], flag leaf size [76], spike length [18], and spikelet number per spike [77]. Contrasting effects of the dwarfing alleles on grain weight have been observed in different genotypes [19], so the lack of differences in grain weight detected in this study are not surprising. By contrast, consistent increases in grain number per spike have been associated with $R H T 1$ dwarfing alleles in multiple genotypes $[18,19]$. These increases were likely driven by increased fertility because no differences in spikelet number per spike were detected in these studies. In our $F_{2}$ and $\mathrm{BC}_{1} \mathrm{~F}_{2}$ populations, the semi-dwarf homozygous RHT-B1b plants also showed more grains per spike than the tall plants homozygous for RHT-B1b $\mathrm{E}_{\mathrm{E} 529 \mathrm{~K}}$ (Table 1), but the differences were not significant (Table 1). We do not know if this lack of significant differences was a result of the partial suppression effect of RHT-B1 $\mathrm{b}_{\mathrm{E} 529 \mathrm{~K}}$ plants on plant height, or because the PFYRE motif plays a smaller role in the DELLA effect on grain number and fertility.

\section{RHT1-mediated GA signaling in wheat}

We found three lines carrying mutations in RHT-B1b that increased height; two independent lines carrying the RHT-B1 $b_{\mathrm{E} 529 \mathrm{~K}}$ point mutation and a mutant line carrying a premature stop codon mutation (W605*) that truncated the last 17 amino acids of RHT-B1b (Figs. 1 and 2). A previous study using RHT-B1c (a stronger dwarfing allele than RHT-B1b) identified five independent mutations in a similar region of the C-terminal GRAS domain that suppressed the dwarfing effect of this allele, including one line carrying the W605* mutation identified in this study. However, these mutants were $2 \%$ to $24 \%$ shorter than the homozygous RHT-B1a plants, suggesting a partial suppression effect [35]. Taken together, these results illustrate the importance of different motifs within the C-terminal GRAS domain in modulating GA-mediated growth responses. The characterization of the mutants described in this study can help define which amino acids within these motifs are involved in different repression functions of RHT-B1.
The GA insensitivity of GA insensitive DELLA domain mutants in Arabidopsis, wheat, barley and maize are all explained by the inability of the mutant DELLA proteins to interact with the GA receptor GID1 [78]. Furthermore, mutations in the DELLA domain in RHT-B1b abolish the interaction with wheat GID1 $[29,79]$ and GID2 [80]. Since the RHT-B1b E529K $_{\text {mutation reported }}$ in this study is in the $\mathrm{C}$-terminal region of the protein and does not restore the truncated DELLA domain, it is unlikely that it will restore the interaction between RHT-B1b and GID1 and its sensitivity to GA. A simpler hypothesis is that the $\mathrm{E} 529 \mathrm{~K}$ mutation weakened some of the repression functions of RHT-B1b allowing expression of some of its target genes. This hypothesis is consistent with the significantly higher number of upregulated $(77 \%)$ than downregulated (23\%) genes in the RHT-B1b $b_{\mathrm{E} 529 \mathrm{~K}}$ mutant relative to the wild-type.

DELLA proteins mediate diverse GA responses mainly through protein-protein interactions, and different subdomains of DELLA interact with distinct subsets of target proteins $[4,81,82]$. It would be interesting to test if the EMS mutations identified here in the different RHT-B1b domains (Additional file 1: Table S5) and in other studies in RHT-B1c [34, 35, 74] affect different subsets of pleiotropic effect. Since no DELLA interacting proteins have been reported so far to specifically interact with the PFYRE domain [4], the mechanism by which the E529K mutation in this motif affects only a subset of the RHT-B1 pleiotropic effects remains unknown.

The RHT-B1b suppressor alleles identified in our study also provide an indirect confirmation of the hypothesis that the semi-dwarf phenotype of the $R h t-B 1 b$ allele arises from translational re-initiation [21]. The reduced GA signaling of $R h t-B 1 b$ is thought to be the result of the re-initiation of translation at one of the subsequent methionine amino acids (i.e., M67, M69, or M71) present after the premature Q64* stop codon. The resulting protein lacking the N-terminal DELLA domain required for the formation of GA-GID1-DELLA complex is hypothesized to be responsible for the GA-insensitive phenotype conferred by RHT-B1b [11, 12, 29]. The suppression of the dwarfing effect of RHT-B1b by our induced mutations in the C-terminal domain provides indirect support for this hypothesis, since this result would not have been possible if there were no translation of RHT-B1b.

\section{Transcriptomic changes induced by RHT-B $1 b_{E 529 K}$}

RNA-seq experiments comparing sister lines encoding RHT-B1b and RHT-B1b $\mathrm{E}_{\mathrm{E} 529 \mathrm{~K}}$ showed that only one out of 229 DEGs between the two genotypes (FDR-adj $P<$ 0.05 in both DEseq2 and EdgeR) overlapped in two or more tissues (Additional file 1: Table S3). A similar result was observed when using a less stringent criterion, considering DEGs that were significant in at least one of 
the two statistical tests (FDR-adj $P<0.05$ in DEseq 2 or EdgeR; Additional file 1: Table S4). Only $4.4 \%$ of the 4,963 DEGs using this criterion overlapped in two or more tissues (Additional file 2: Figure S3). Our results parallel previous reports in Arabidopsis showing that DELLAs regulate distinct sets of genes in different organs and developmental stages $[81,82]$.

DELLA proteins do not possess canonical DNA binding domains and control the expression of downstream GA response genes mainly through physical interactions with transcription factors and transcriptional regulators $[4,83]$. Therefore, it is logical to speculate that the transcriptomic changes induced by RHT-B1 $\mathrm{b}_{\mathrm{E} 529 \mathrm{~K}}$ are probably associated to disrupted protein-protein interaction. Weaker interaction between DELLA and these proteins would result in increased expression of the downstream GA response genes, thus stimulating growth. It would be interesting to investigate the effect of the E529K mutation on the strength of yeast-two hybrid interactions with known DELLA partners (reviewed in [4]).

GA promotes growth by enhancing the expression of genes involved in cell expansion and cell proliferation, and DELLA negatively regulates these processes in organ- and developmental stage-dependent manners [82, 84-86]. In agreement with previously published results, we found that two genes encoding FARs potentially involved in cell wall lipid synthesis [41, 42] were upregulated in the coleoptiles of homozygous RHT-B1b $\mathrm{E}_{\mathrm{E} 529 \mathrm{~K}}$ plants. Similarly, five genes encoding cell wall protein AGPs involved in cell expansion and stem elongation [53-55] were upregulated at Z49 in peduncles of plants encoding the RHT-B1b $\mathrm{E}_{\mathrm{E} 529 \mathrm{~K}}$ allele. By contrast, a number of genes promoting cell proliferation were downregulated in the same plants. These results suggest that the increased peduncle length observed in plants encoding RHT-B1b $b_{\mathrm{E} 529 \mathrm{~K}}$ is likely associated with increased cell expansion rather than cell proliferation.

Carbohydrate metabolism modulated by GA signaling is also an important determinant in plant growth $[87,88]$. This was reflected in the upregulation of many genes involved in photosynthesis and respiration in the peduncles of homozygous RHT-B1 $\mathrm{b}_{\mathrm{E} 529 \mathrm{~K}}$ plants at Z52. These include genes encoding CA required for photosynthetic $\mathrm{CO}_{2}$ fixation [57], FBA involved in Calvin cycle and glycolysis [58, 89], SPS involved in catalyzing sucrose biosynthesis [59], GAPDH and PFP involved in glycolysis [60, 61], and dihydrolipoyl dehydrogenase involved in the Krebs cycle [62] (Table 2). Interestingly, the modulation of the expression of some of these genes is known to induce changes in plant growth. For example, transgenic tobacco plants overexpressing FBA exhibited increased stem length and biomass [90], while FBA knockdown in tomato decreased stem diameter, biomass, and seed size [91]. Also, overexpression of SPS in rice [92] and tobacco [93] was associated with a significant increase in plant height.

Finally, DELLAs mediate signals from multiple hormone pathways by interacting with multiple hormone signaling molecules [94]. For example, DELLAs modulate auxin signaling by interacting with auxin response factors that regulate expression of auxin response genes [95]. DELLAs also affect strigolactone (SL) signaling by interacting with the SL receptor DWARF14 [9]. In this study, we observed increased transcript levels of auxin and SL pathway-related genes (e.g. ILR1, auxin influx transporter, and carotenoid cleavage dioxygenase; Table 2) in the plants encoding RHT-B1b $\mathrm{E}_{\mathrm{E} 29 \mathrm{~K} \text {. }}$ These results reflect DELLA's role in integrating signals from different hormone pathways. GA and JA signaling jointly regulate growth and defense balance responding to developmental and environmental cues, and this is largely mediated by the DELLA's interaction with JAZ proteins, which are negative regulators of JA signaling [8]. Many defense-related genes differentially expressed in plants encoding RHT-B1b ${ }_{\mathrm{E} 529 \mathrm{~K}}$ in our study (Table 2) may reflect the roles of DELLA in the integration of JA and GA signaling.

The absence of known GA targets among the wheat DEGs between RHT-B1b and RHT-B1 $1_{\mathrm{E} 529 \mathrm{~K}}$ is not surprising considering that the E529K mutation showed only a mild response to $\mathrm{GA}_{3}$. The coleoptile experiments at different $\mathrm{GA}_{3}$ concentration showed significant coleoptile length increase in RHT-B1 $1_{\mathrm{E} 529 \mathrm{~K}}$ only under the highest $\mathrm{GA}_{3}$ concentration, and the effects were smaller than in the plants carrying the wild-type RHT-B1a or the RHT-B1-null alleles (Fig. 5). A meta-transcriptome analysis using 12 Arabidopsis transcriptome data sets found limited DEG overlap among different data sets, likely reflecting the tissue specificity of GA responses [82]. In spite of the limited overlap, this meta-transcriptome analysis observed some shared DEGs involved in GA metabolism/signaling, cell cycle, cell wall, and auxin metabolism / transport / signaling. Several of the wheat DEGs detected in this study between RHT-B1 and RHT-B1b $\mathrm{E}_{\mathrm{E} 29 \mathrm{~K}}$ are involved in similar processes (cell cycle, cell wall, auxin pathway) suggesting some conservation in the general processes affected by DELLAs in different species. The study of the functions of the DEGs (both shared and wheat-specific) identified in this study would be facilitated by the availability of new reverse genetics tools such as the wheat sequenced TILLING populations [38] and the implementation of CRISPR/Cas9 in wheat $[96,97]$.

\section{Conclusions}

In summary, this study identified an induced wheat mutant encoding the RHT-B1b $\mathrm{E}_{\mathrm{E} 529 \mathrm{~K}}$ hypomorphic allele, which partially suppressed the dwarfing effect of RHT-B1b. The intermediate plant height and coleoptile length resulting from this allele may be of interest to wheat breeding programs for water-limited regions. In 
addition, the significant effects of the E529K mutation provides indirect evidence that the RHT-B1b translation is re-initiated after the premature stop codon in the N-terminal DELLA domain. Our RNA-seq experiment showed that most of the changes in gene transcript levels between plants encoding RHT-B1b $\mathrm{E}_{\mathrm{E} 529 \mathrm{~K}}$ or RHT-B1b were tissue specific, and identified distinct sets of potential DELLA down-steam target genes involved in cell wall and carbohydrate metabolisms, cell cycle/division, and hormone pathways.

\section{Methods}

\section{Plant material and phenotype evaluation}

We identified a tall mutant line 'T4-934' during the generation advancement of an EMS-induced tetraploid wheat (var. Kronos) TILLING population [36] grown in the field at the University of California, Davis, CA $\left(38^{\circ}\right.$ $32^{\prime} \mathrm{N}, 121^{\circ} 46^{\prime} \mathrm{W}$ ) in 2013. Candidate sequencing of the C-terminal region of $R H T-B 1$ (see "RHT-B1 sequencing and marker development" section below) showed that line T4-934 carries an induced mutation that results in a change from glutamate (E) to lysine $(\mathrm{K})$ at position 529 (RHT-B1b E529K $_{2}$ ) in the PFYRE motif.

Using marker-assisted selection, T4-934 was backcrossed with the non-mutagenized variety 'Kronos' carrying Rht-B1b, to generate $\mathrm{F}_{2}(\mathrm{n}=84)$ and $\mathrm{BC}_{1} \mathrm{~F}_{2}(\mathrm{n}=119)$ populations segregating for the alleles encoding RHT-B1b

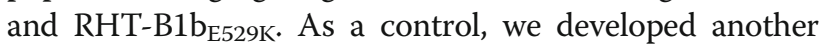
$\mathrm{BC}_{1} \mathrm{~F}_{2}(\mathrm{n}=158)$ population from the cross Kronos"2/ Gredho (PI 532239, RHT-B1a) segregating for the GA-sensitive RHT-B1a and insensitive RHT-B1b alleles. The three populations were sown in one-meter rows (five plants per row) in the field at the University of California, Davis, in November 2014 and were harvested in June 2015. Days to heading was measured as the number of days from sowing to the full emergence of the first spike. Fifteen days after all plants finished heading, the number of above-ground internodes, internode length, flag leaf length and width were measured as the average values from the three tallest tillers in each plant. Tiller number per plant was also measured. Plant height was measured as length from the ground to the top of the spike of the tallest tiller, excluding awns. Upon maturity, spikes from the three tallest tillers were harvested to measure spike length, spikelet number per spike, and grain number per spike. The averages from three spikes were used to represent an individual plant. Grain weight from the three spikes was used to calculate 1,000 grain weight.

The effect of RHT-B1 $\mathrm{b}_{\mathrm{E} 529 \mathrm{~K}}$ on germination rate, coleoptile length, seedling shoot and root lengths were evaluated using $\mathrm{BC}_{1} \mathrm{~F}_{3}$ sister lines homozygous for the RHT-B1b $_{\mathrm{E} 529 \mathrm{~K}}$ or RHT-B1b alleles. For germination rate, 50 seeds of each $\mathrm{BC}_{1} \mathrm{~F}_{3}$ sister line (five homozygous RHT-B1b and five homozygous RHT-B1b $\mathrm{E}_{\mathrm{E} 529 \mathrm{~K}}$ lines) were sown on petri dishes with distilled water, kept at $4^{\circ}$ $\mathrm{C}$ for $24 \mathrm{~h}$. Germinating seeds were moved to a growth chamber with $16 \mathrm{~h}$ of light (intensity $230 \mu \mathrm{M} \mathrm{m}^{-2} \mathrm{~s}^{-1}$ ) at $22^{\circ} \mathrm{C}$ and $8 \mathrm{~h}$ night condition at $18^{\circ} \mathrm{C}$. The number of seeds with at least $2 \mathrm{~mm}$ radicle emergence were counted every $8 \mathrm{~h}$. The same $\mathrm{BC}_{1} \mathrm{~F}_{3}$ sister lines were sown $2.5 \mathrm{~cm}$ below the top of germination paper $(26 \mathrm{~cm}$ $\times 13 \mathrm{~cm}$ ) moistened with distilled water, rolled and kept upright with the bottom $4 \mathrm{~cm}$ of the paper soaked in distilled water at $4^{\circ} \mathrm{C}$ for $24 \mathrm{~h}$, and moved to the growth chamber with the same conditions as described above. Coleoptile, shoot and root lengths were measured 2 weeks after sowing. Coleoptile length was determined as the distance between the embryo and the tip of coleoptile. Shoot and root lengths were determined as the distances between the embryo and the tips of the first leaf and the longest root, respectively.

The GA sensitivity assay was conducted using non-mutagenized Kronos (RHT-B1b), a tetraploid variety 'Gredho' (RHT-B1a), an $\mathrm{M}_{4}$ Kronos mutant line 'T4-3822' homozygous for a deletion encompassing the entire RHT-B1 gene [40], and $\mathrm{BC}_{1} \mathrm{~F}_{3}$ sister lines of 'Kronos*2/ T4-934' homozygous for the RHT-B1b $\mathrm{b}_{\mathrm{E} 529 \mathrm{~K}}$ mutation. The seeds were sown on germination paper as described above, kept at $4^{\circ} \mathrm{C}$ for $48 \mathrm{~h}$, and moved to $\mathrm{GA}_{3}$ (Sigma-Aldrich, St. Louis, MO, USA) solutions with different concentrations $(0,0.1,1.0$, and $10 \mu \mathrm{M})$ under room temperature. After 10 days, coleoptile and shoot length was measured. The GA response index (GRI) was determined as the percent length increase under the highest GA concentration (10 $\mu \mathrm{M})$ relative to the control $(0 \mu \mathrm{M})$. The experiment was conducted as a randomized complete block design with four blocks, one replication (eight subsamples) per block and treatment combination.

By searching the sequenced tetraploid wheat TILLING database ([38]; https://dubcovskylab.ucdavis.edu/wheat_blast), six additional nonsynonymous mutations were identified in the distal region of the C-terminal RHT-B1b including the SAW and part of PFYRE motifs. $\mathrm{M}_{4}$ lines $(n=16-18)$ segregating for each of the six mutations were grown in cone-shaped pots with $6.9 \mathrm{~cm}$ diameter and $25.4 \mathrm{~cm}$ depth in the greenhouse. Plant height was measured upon maturity as described above.

\section{Statistical analysis}

One-way ANOVAs were conducted on each agronomic trait evaluated in the field for the $\mathrm{F}_{2}$ and $\mathrm{BC}_{1} \mathrm{~F}_{2}$ populations, using the RHT-B1 genotype as a single factor. Mean comparisons were conducted using Tukey's multiple comparison tests. Similarly, one-way ANOVAs were conducted on plant height for the $\mathrm{M}_{4}$ populations segregating for each additional RHT-B1 mutation. T-tests were conducted to analyze germination and seedling traits from the experiment conducted in the growth chamber. For the 
GA sensitivity assay, an ANOVA was conducted using GA concentration as a fixed factor and blocks as a random factor, followed by Dunnett's multiple comparison tests against the control without GA. For all ANOVAs, data violating ANOVA assumptions (normality of residuals by Shapiro-Wilk test, and homogeneity of variances by Levene's test) were transformed using power transformations. After the statistical analyses, means for graphs and tables were de-transformed to the original scale. All statistical analyses were carried out using SAS 9.4 Software (SAS Institute, Cary, NC).

\section{RHT-B1 sequencing and marker development}

A pair of genome-specific primers (forward: 5'-GACT CCTCCTGCAGCACCTA-3'; reverse: 5'-AACCCGGCG TTGCCGAGG-3') were designed to sequence the C-terminal region of RHT-B1 (433 - 1,697 bp region from the start codon). PCR was conducted in $20 \mu \mathrm{l}$ total reaction volume with 50-100 ng template DNA, 0.25 $\mu \mathrm{M}$ of forward and reverse primers, $0.1 \mathrm{mM}$ of each dNTP, $0.8 \mu \mathrm{l} \mathrm{Taq}$ polymerase, $1.5 \mathrm{mM} \mathrm{MgCl}_{2}, 5 \%$ DMSO, and 10x PCR buffer. PCR was comprised of the initial denaturation at $94^{\circ} \mathrm{C}(5 \mathrm{~min}), 40$ cycles of $94^{\circ} \mathrm{C}$ (20 sec), $60^{\circ} \mathrm{C}(30 \mathrm{sec})$, and $72^{\circ} \mathrm{C}(1 \mathrm{~min})$, followed by the final extension at $72^{\circ} \mathrm{C}(7 \mathrm{~min})$. Before sequencing, 5 $\mu \mathrm{l}$ PCR product was purified as described previously [98]. The purified PCR product was sequenced using BigDye Terminator v3.1 Sequencing Standard Kit (Applied Biosystems, Foster City, CA) and an ABI-3730 DNA Sequencer (Applied Biosystems, Foster City, CA).

A CAPS (cleaved amplified polymorphic sequences) marker was designed to screen for the mutant RHT-B1b $b_{\mathrm{E} 529 \mathrm{~K}}$ allele. The PCR product, amplified using the same primers and conditions described above, was digested with the restriction enzyme StyI. The wild-type allele produced an undigested 1,265 bp fragment and the RHT-B1 $b_{\mathrm{E} 529 \mathrm{~K}}$ allele produced two fragments of 1,153 bp and $112 \mathrm{bp}$, which were visualized by agarose gel electrophoresis (Additional file 2: Figure S4).

To genotype the six additional RHT-B1 mutations, an additional reverse primer was designed in the 3' UTR (5'-CTTCTTCTTCTTCAAGAGCG-3') and used along with the same forward primer described above, to amplify the 1,434 bp distal region of Rht-B1b and $115 \mathrm{bp}$ of the 3'-UTR. PCR and sequencing were conducted as described above.

\section{RNA-seq experiments}

$\mathrm{BC}_{1} \mathrm{~F}_{3}$ seeds derived from a single heterozygous $\mathrm{BC}_{1} \mathrm{~F}_{2}$ plant (RHT-B1b/RHT-B1b $\mathrm{b}_{\mathrm{E} 529 \mathrm{~K}}$ ) were used for the RNA-seq experiments. The seeds were sown on germination paper as described above, kept at $4^{\circ} \mathrm{C}$ for $48 \mathrm{~h}$, and moved to a growth chamber with $16 \mathrm{~h}$ light $\left(230 \mu \mathrm{M} \mathrm{m}^{-2} \mathrm{~s}^{-1}\right.$ intensity) at $22^{\circ} \mathrm{C}$ and $8 \mathrm{~h}$ dark at $18^{\circ} \mathrm{C}$. Ten days after sowing (DAS), seedlings were transplanted into plastic pots and grown in the same growth chamber conditions.

We sampled tissue at four different developmental points as defined in the Zadoks' scale [99]: Z07 coleoptile (7 DAS), Z11 first leaf (10 DAS), Z49 peduncle when first awn appears (40 DAS), and Z52 peduncle when first spikelet appears (46 DAS). Using the CAPS marker described above, homozygous RHT-B1b and homozygous RHT-B1b $\mathrm{b}_{\mathrm{E} 29 \mathrm{~K}}$ sister lines were selected and used for the RNA-seq experiments.

Four biological replicates were used per genotype at each time point. Samples were ground to a fine powder in liquid nitrogen, and total RNA was extracted using the Spectrum ${ }^{\mathrm{TM}}$ Plant Total RNA Kit (Sigma-Aldrich, St. Louis, MO). RNA-seq libraries were constructed using the TruSeq RNA Sample Preparation Kit v2 (Illumina, San Diego, CA) following the manufacturer's instructions, and each library was indexed using NEXTflex-96 ${ }^{\text {TM }}$ DNA Barcode (Bioo Scientific, Austin, TX) for multiplexed sequencing reactions. The libraries were sequenced on the HiSeq 3000 platform (Illumina, San Diego, CA, USA) using the single-end $100 \mathrm{bp}$ (SE 100) module at the UC Davis Genome Center.

Sequencing data were analyzed as previously described [100]. Briefly, raw reads were trimmed using 'Sickle' (version 1. 33, https://github.com/najoshi/sickle with default parameters except -1 25 -q 25) and 'Scythe' (version 0. 991, https://github.com/vsbuffalo/scythe with default parameters). The processed reads were mapped to the IWGSC RefSeq v1.0 Chinese Spring reference genome (https://urgi.versailles.inra.fr/download/iwgsc/IWG-

SC_RefSeq_Assemblies/v1.0/) using 'GSNAPl' (version 2016-11-07, with default parameters except -m 5 -n 1 -N 1 -A sam, [101]). We excluded the D genome sequences from the reference before mapping the processed reads of the tetraploid lines (A and B genomes). Raw counts per transcript were calculated using 'htseq-count' (version 0.6.1, with default parameters except $-\mathrm{m}$ union -a 30 -t gene, [102]) with the GFF3 (General Feature Format version 3) file from the IWGSC RefSeq v1.0 annotation (199,680 features including high and low confidence genes and lncRNAs) and the SAM (Sequence Alignment/Mapping) files from each sample. Only transcripts with three or more reads in at least two biological replicates were retained using an $\mathrm{R}$ package 'noleaven' (https://github.com/topherconley/noleaven).

Raw counts were normalized using 'DESeq2' (version 1.18.1, [103]), and differentially expressed genes (DEGs) were identified between homozygous RHT-B1b and RHT-B1b $b_{\text {E529K }}$ plants at each tissue/time point using 'DESeq2' and 'EdgeR' (version 3.20.6, [104]). Significant DEGs were selected using an adjusted false discovery rate threshold of $P<0.05$ in both methods (FDR-adj $P$; 
[105]). Functional annotation and gene ontology (GO) enrichment analysis for DEGs were conducted as previously described [100]. DEGs shared among different tissues were identified and visualized with UpSet plots [106] using an R package 'UpSetR' (version 1.4.0, [107]).

\section{Additional files}

Additional file 1: Table S1. Effects of additional induced mutations in the C-terminal of RHT-B1 on plant height. Table S2. RNA-seq data summary of 32 libraries. Table S3. Differentially expressed genes between

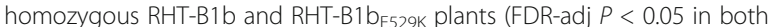
DESeq2 and EdgeR). Table S4. Differentially expressed genes between homozygous RHT-B1b and RHT-B1 b $_{\text {E529k }}$ plants (FDR-adj $P<0.05$ in DESeq2 or EdgeR). Table S5. EMS-induced nonsynonymous mutations in conserved RHT-B1 motifs. (XLSX $551 \mathrm{~kb}$ )

Additional file 2: Figure S1. Number of differentially regulated genes (DEGs) between plants encoding RHT-B1b and RHT-B1 b $529 \mathrm{~K}_{\text {identified by }}$ DESeq2 or EdgeR in (a) coleoptile, (b) first leaf, (c) Z49 peduncle, and (d) Z52 peduncle. Upregulated and downregulated DEGs are in red and blue, respectively. Figure S2. Expression of RHT-B1 (TraesCS4B01G043100) in plants encoding RHT-B1 $\mathrm{b}$ and RHT-B1 $\mathrm{b}_{5529 \mathrm{~K}}$ in coleoptile, first leaf, Z49 and Z52 peduncle. Normalized counts were obtained from the RNA-seq data. NS: not significant according to the t-test. Error bars indicate \pm 1 standard error. Figure S3. UpSet plots showing the numbers of differentially expressed genes (DEGs) between homozygous RHT-B1b and RHT$B 1 b_{E 529 K}$ plants that are unique or overlapping among four different tissues. DEGs significant (FDR-adj $P<0.05$ ) in either DESeq2 or EdgeR were counted. (a) Number of upregulated DEGs. (b) Number of downregulated DEGs. Figure S4. An example genotyping result of the CAPS marker developed to detect the RHT-B1 $\mathrm{b}_{5529 \mathrm{~K}}$ mutation. W: homozygous RHT-B1b, $M$ : homozygous RHT-B1 $\mathrm{b}_{\mathrm{E} 529 \mathrm{k}}, \mathrm{H}$ : heterozygote (DOCX $312 \mathrm{~kb}$ )

\section{Abbreviations \\ AGP: ARABINOGALACTAN PROTEIN; CA: CARBONIC ANHYDRASE; \\ DEG: differentially expressed gene; EMS: ethyl methanesulfonate; FAR: FATTY ACYL-COENZYME A REDUCTASE; FBA: FRUCTOSE-BISPHOSPHATE ALDOLASE; FDR: false discovery rate; GA: gibberellin; GAPDH: GLYCERALDEHYDE-3- PHOSPHAGE DEHYDROGENASE; GID1: GIBBERELLIN INSENSITIVE DWARF1; GO: gene ontology; GRAS: GAI, RGA, and SCR; GRI: GA response index; JA: jasmonic acid; LHR: leucine heptad repeat; LOB: lateral organ boundary; PFP: PYROPHOSPHATE:FRUCTOSE 6-PHOSPHATE 1-PHOSPHOTRANSFERASE: SL: strigolactone; SPS: SUCROSE-PHOSPHATE SYNTHASE; TILLING: targeting induced local lesions in genomes}

\section{Acknowledgements}

We thank the International Wheat Genome Sequencing Consortium for pre-publication access to the RefSeq v1.0 Chinese Spring reference sequences.

\section{Funding}

This project was supported by the Agriculture and Food Research Initiative Competitive Grant 2017-67007-25939 (WheatCAP) from the USDA National Institute of Food and Agriculture and the Howard Hughes Medical Institute. Y. Mo is a Howard Hughes Medical Institute's International Student Research fellow and a Monsanto Beachell-Borlaug International scholar. The funding bodies played no role in the design, execution, interpretation of the data, or writing of the manuscript.

\section{Availability of data and materials}

RNA-seq reads generated in this study are available in NCBI's Sequence Read Archive (https://www.ncbi.nlm.nih.gov/sra, Bioproject PRJNA435752). Seeds of the RHT-B1 $\mathrm{b}_{\text {E529K }}$ mutant have been deposited in the USDA-ARS National Plant Germplasm System (NPGS) as accession PI 687144 (https://npgsweb.ars-grin.gov/gringlobal/accessiondetail.aspx?id=1961292).

\section{Authors' contributions}

JD and SP identified the Kronos tall mutants. SP designed molecular markers. YM performed phenotypic evaluations and RNA-seq experiments and wrote the first draft of the manuscript. SP and JD designed the study, contributed to data analysis, and revised the manuscript. All authors have read and approved the final version of the manuscript.

Ethics approval and consent to participate

Not applicable

\section{Consent for publication}

Not applicable

\section{Competing interests}

The authors declare that they have no competing interests.

\section{Publisher's Note}

Springer Nature remains neutral with regard to jurisdictional claims in published maps and institutional affiliations.

\section{Author details}

1 Department of Plant Sciences, University of California, Davis, CA 95616, USA. ${ }^{2}$ Department of Soil and Crop Sciences, Colorado State University, Fort Collins, CO 80523, USA. ${ }^{3}$ National Institute of Crop Science, Rural Development Administration, Wanju 55365, South Korea. ${ }^{4}$ Howard Hughes Medical Institute, Chevy Chase, MD 20815, USA.

Received: 29 April 2018 Accepted: 3 October 2018

Published online: 22 October 2018

\section{References}

1. Hauvermale AL, Ariizumi T, Steber CM. Gibberellin signaling: a theme and variations on DELLA repression. Plant Physiol. 2012;160(1):83-92.

2. Yamaguchi S. Gibberellin metabolism and its regulation. Annu Rev Plant Biol. 2008:59:225-51.

3. Hedden P, Thomas SG. Gibberellin biosynthesis and its regulation. Biochem J. 2012:444:11-25.

4. van de Velde K, Ruelens P, Geuten K, Rohde A, van der Straeten D. Exploiting DELLA signaling in cereals. Trends Plant Sci. 2017;22(10):880-93.

5. de Lucas $\mathrm{M}$, Davière JM, Rodríguez-Falcón $\mathrm{M}$, Pontin $\mathrm{M}$, Iglesias-Pedraz JM, Lorrain S, Fankhauser C, Blázquez MA, Titarenko E, Prat S. A molecular framework for light and gibberellin control of cell elongation. Nature. 2008;451(7177):480-4.

6. Feng SH, Martinez C, Gusmaroli G, Wang Y, Zhou JL, Wang F, Chen LY, Yu L, Iglesias-Pedraz JM, Kircher S, Schäfer E, Fu XD, Fan LM, Deng XW. Coordinated regulation of Arabidopsis thaliana development by light and gibberellins. Nature. 2008:451(7177):475-9.

7. Bai MY, Shang JX, Oh E, Fan M, Bai Y, Zentella R, Sun TP, Wang ZY. Brassinosteroid, gibberellin and phytochrome impinge on a common transcription module in Arabidopsis. Nat Cell Biol. 2012;14(8):810-7.

8. Hou XL, Lee LYC, Xia KF, Yen YY, Yu H. DELLAs modulate jasmonate signaling via competitive binding to JAZs. Dev Cell. 2010;19(6):884-94

9. Nakamura H, Xue YL, Miyakawa T, Hou F, Qin HM, Fukui K, Shi X, Ito E, Ito S, Park SH, Miyauchi Y, Asano A, Totsuka N, Ueda T, Tanokura M, Asami T. Molecular mechanism of strigolactone perception by DWARF14. Nat Commun. 2013;4:2613.

10. Fukazawa J, Teramura H, Murakoshi S, Nasuno K, Nishida N, Ito T, Yoshida M, Kamiya Y, Yamaguchi S, Takahashi Y. DELLAs function as coactivators of GAlASSOCIATED FACTOR1 in regulation of gibberellin homeostasis and signaling in Arabidopsis. Plant Cell. 2014;26(7):2920-38.

11. Ueguchi-Tanaka M, Nakajima M, Motoyuki A, Matsuoka M. Gibberellin receptor and its role in gibberellin signaling in plants. Annu Rev Plant Biol. 2007;58:183-98.

12. Murase $K$, Hirano $Y$, Sun TP, Hakoshima T. Gibberellin-induced DELLA recognition by the gibberellin receptor GID1. Nature. 2008;456(7221):459-63.

13. Sasaki A, Itoh H, Gomi K, Ueguchi-Tanaka M, Ishiyama K, Kobayashi M, Jeong $\mathrm{DH}, \mathrm{An} \mathrm{G}$, Kitano H, Ashikari M, Matsuoka M. Accumulation of phosphorylated repressor for gibberellin signaling in an F-box mutant Science. 2003;299(5614):1896-8.

14. Sun XL, Jones WT, Harvey D, Edwards PJB, Pascal SM, Kirk C, Considine T, Sheerin DJ, Rakonjac J, Oldfield CJ, Xue B, Dunker AK, Uversky VN. Nterminal domains of DELLA proteins are intrinsically unstructured in the absence of interaction with GID1/gibberellic acid receptors. J Biol Chem. 2010;285(15):11557-71. 
15. Sun $\mathrm{XL}$, Jones $\mathrm{WT}$, Rikkerink EHA. GRAS proteins: the versatile roles of intrinsically disordered proteins in plant signalling. Biochem J. 2012;442:1-12.

16. Yoshida H, Hirano K, Sato T, Mitsuda N, Nomoto M, Maeo K, Koketsu E, Mitani R, Kawamura M, Ishiguro S, Tada Y, Ohme-Takagi M, Matsuoka M, Ueguchi-Tanaka M. DELLA protein functions as a transcriptional activator through the DNA binding of the INDETERMINATE DOMAIN family proteins. Proc Natl Acad Sci U S A. 2014;111(21):7861-6.

17. Hedden P. The genes of the Green Revolution. Trends Genet. 2003;19(1):5-9.

18. Youssefian S, Kirby EJM, Gale MD. Pleiotropic effects of the GA-insensitive Rht dwarfing genes in wheat. 2. Effects on leaf, stem, ear and floret growth. Field Crops Res. 1992;28(3):191-210.

19. Flintham JE, Börner A, Worland AJ, Gale MD. Optimizing wheat grain yield: Effects of Rht (gibberellin-insensitive) dwarfing genes. J Agr Sci. 1997;128:11-25

20. Evenson RE, Gollin D. Assessing the impact of the Green Revolution, 1960 to 2000. Science. 2003;300(5620):758-62.

21. Peng J, Richards DE, Hartley NM, Murphy GP, Devos KM, Flintham JE, Beales J, Fish L, Worland AJ, Pelica F, Sudhakar D, Christou P, Snape JW, Gale MD, Harberd NP. 'Green revolution' genes encode mutant gibberellin response modulators. Nature. 1999:400(6741):256-61.

22. Evans LT. Feeding the ten billion. Plant and population growth. Cambridge: Cambridge University Press; 1998.

23. Guedira M, Brown-Guedira G, van Sanford D, Sneller C, Souza E, Marshall D. Distribution of Rht genes in modern and historic winter wheat cultivars from the Eastern and Central USA. Crop Sci. 2010;50(5):1811-22.

24. Rebetzke GJ, Richards RA, Fettell NA, Long M, Condon AG, Forrester RI, Botwright TL. Genotypic increases in coleoptile length improves stand establishment, vigour and grain yield of deep-sown wheat. Field Crops Res. 2007;100(1):10-23.

25. Rebetzke GJ, Appels R, Morrison AD, Richards RA, McDonald G, Ellis MH, Spielmeyer W, Bonnett DG. Quantitative trait loci on chromosome 4B for coleoptile length and early vigour in wheat (Triticum aestivum L.). Aust J Agr Res. 2001;52(11-12):1221-34.

26. Srinivasachary GN, Steed A, Simmonds J, Leverington-Waite M, Wang Y, Snape $J$, Nicholson P. Susceptibility to Fusarium head blight is associated with the Rht-D1b semi-dwarfing allele in wheat. Theor Appl Genet. 2008;116(8):1 145-53.

27. Srinivasachary GN, Steed A, Hollins TW, Bayles R, Jennings P, Nicholson P. Semidwarfing Rht-B1 and Rht-D1 loci of wheat differ significantly in their influence on resistance to Fusarium head blight. Theor Appl Genet. 2009;1 18(4):695-702.

28. Wen W, Deng QY, Jia HY, Wei LZ, Wei JB, Wan HS, Yang LM, Cao WJ, Ma $Z Q$. Sequence variations of the partially dominant DELLA gene Rht-B1C in wheat and their functional impacts. J Exp Bot. 2013;64(11):3299-312.

29. Pearce S, Saville R, Vaughan SP, Chandler PM, Wilhelm EP, Sparks CA, Al-Kaff N, Korolev A, Boulton MI, Phillips AL, Hedden P, Nicholson P, Thomas SG. Molecular characterization of Rht-1 dwarfing genes in hexaploid wheat. Plant Physiol. 2011;157(4):1820-31.

30. Divashuk MG, Vasilyev AV, Bespalova LA, Karlov Gl. Identity of the Rht-11 and Rht-Ble reduced plant height genes. Russ J Genet. 2012;48(7):761-3.

31. Bazhenov MS, Divashuk MG, Amagai Y, Watanabe N, Karlov GI. Isolation of the dwarfing Rht-B1p (Rht17) gene from wheat and the development of an allele-specific PCR marker. Mol Breed. 2015;35(11):213.

32. Wilhelm EP, Mackay IJ, Saville RJ, Korolev AV, Balfourier F, Greenland AJ, Boulton MI, Powell W. Haplotype dictionary for the Rht-1 loci in wheat. Theor Appl Genet. 2013;126(7):1733-47.

33. Li A, Yang W, Lou X, Liu D, Sun J, Guo X, Wang J, Li Y, Zhan K, Ling HQ, Zhang A. Novel natural allelic variations at the Rht-1 loci in wheat. J Integr Plant Biol. 2013;55(11):1026-37.

34. Chandler PM, Harding CA. 'Overgrowth' mutants in barley and wheat: new alleles and phenotypes of the 'Green Revolution' DELLA gene. J Exp Bot. 2013;64(6):1603-13.

35. Derkx AP, Harding CA, Miraghazadeh A, Chandler PM. Overgrowth (Della) mutants of wheat: development, growth and yield of intragenic suppressors of the Rht-B1C dwarfing gene. Funct Plant Biol. 2017:44(5):525-37.

36. Uauy C, Paraiso F, Colasuonno P, Tran RK, Tsai H, Berardi S, Comai L, Dubcovsky J. A modified TILLING approach to detect induced mutations in tetraploid and hexaploid wheat. BMC Plant Biol. 2009;9:115.

37. Kumar P, Henikoff $S, \mathrm{Ng} P$ P. Predicting the effects of coding non-synonymous variants on protein function using the SIFT algorithm. Nat Protoc. 2009;4(7):1073-82.

38. Krasileva KV, Vasquez-Gross HA, Howell T, Bailey P, Paraiso F, Clissold L, Simmonds J, Ramirez-Gonzalez RH, Wang XD, Borrill P, Fosker C, Ayling S, Phillips AL, Uauy C, Dubcovsky J. Uncovering hidden variation in polyploid wheat. Proc Natl Acad Sci U S A. 2017;114(6):E913-21.
39. Falconer D. Introduction to quantitative genetics. London: Oliver and Boyd; 1960.

40. Mo YJ, Howell T, Vasquez-Gross H, de Haro LA, Dubcovsky J, Pearce S. Mapping causal mutations by exome sequencing in a wheat TILLING population: a tall mutant case study. Mol Genet Genomics. 2018;293(2):463-77.

41. Domergue F, Vishwanath SJ, Joubés J, Ono J, Lee JA, Bourdon M, Alhattab R, Lowe C, Pascal S, Lessire R, Rowland O. Three Arabidopsis fatty acyl-coenzyme A reductases, FAR1, FAR4, and FAR5, generate primary fatty alcohols associated with suberin deposition. Plant Physiol. 2010;153(4):1539-54.

42. Rowland O, Domergue F. Plant fatty acyl reductases: Enzymes generating fatty alcohols for protective layers with potential for industrial applications. Plant Sci. 2012;193:28-38.

43. Puthoff DP, Sardesai N, Subramanyam S, Nemacheck JA, Williams CE. Hfr-2, a wheat cytolytic toxin-like gene, is up-regulated by virulent Hessian fly larval feeding. Mol Plant Pathol. 2005;6(4):411-23.

44. Xu C, Luo F, Hochholdinger F. LOB domain proteins: beyond lateral organ boundaries. Trends Plant Sci. 2016;21(2):159-67.

45. Ross S, Giglione C, Pierre M, Espagne C, Meinnel T. Functional and developmental impact of cytosolic protein $\mathrm{N}$-terminal methionine excision in Arabidopsis. Plant Physiol. 2005;137(2):623-37.

46. McHale L, Tan X, Koehl P, Michelmore RW. Plant NBS-LRR proteins: adaptable guards. Genome Biol. 2006;7(4):212.

47. Boyes DC, Nam J, Dangl JL. The Arabidopsis thaliana RPM1 disease resistance gene product is a peripheral plasma membrane protein that is degraded coincident with the hypersensitive response. Proc Natl Acad Sci U S A. 1998;95(26):15849-54.

48. Fukuoka S, Saka N, Koga H, Ono K, Shimizu T, Ebana K, Hayashi N, Takahashi A, Hirochika H, Okuno K, Yano M. Loss of function of a proline-containing protein confers durable disease resistance in rice. Science. 2009;325(5943): 998-1001.

49. Shiu SH, Bleecker AB. Plant receptor-like kinase gene family: diversity, function, and signaling. Sci STKE. 2001;2001(113):re22.

50. Li Y, Baldauf S, Lim EK, Bowles DJ. Phylogenetic analysis of the UDPglycosyltransferase multigene family of Arabidopsis thaliana. J Biol Chem. 2001;276(6):4338-43.

51. Ross J, Li Y, Lim E, Bowles DJ. Higher plant glycosyltransferases. Genome Biol. 2001;2(2):reviews3004.1.

52. LeClere S, Tellez R, Rampey RA, Matsuda SP, Bartel B. Characterization of a family of IAA-amino acid conjugate hydrolases from Arabidopsis. J Biol Chem. 2002;277(23):20446-52.

53. Willats WG, Knox JP. A role for arabinogalactan-proteins in plant cell expansion: evidence from studies on the interaction of $\beta$-glucosyl Yariv reagent with seedlings of Arabidopsis thaliana. Plant J. 1996;9(6):919-25.

54. Park MH, Suzuki Y, Chono M, Knox JP, Yamaguchi I. CSAGP1, a gibberellinresponsive gene from cucumber hypocotyls, encodes a classical arabinogalactan protein and is involved in stem elongation. Plant Physiol. 2003;131(3):1450-9.

55. Lee KJ, Sakata Y, Mau SL, Pettolino F, Bacic A, Quatrano RS, Knight CD, Knox JP. Arabinogalactan proteins are required for apical cell extension in the moss Physcomitrella patens. Plant Cell. 2005;17(11):3051-65.

56. Kim JH, Tsukaya H. Regulation of plant growth and development by the GROWTH-REGULATING FACTOR and GRF-INTERACTING FACTOR duo. J Exp Bot. 2015;66(20):6093-107.

57. Badger MR, Price GD. The role of carbonic anhydrase in photosynthesis. Annu Rev Plant Phys. 1994;45:369-92.

58. Marsh JJ, Lebherz HG. Fructose-bisphosphate aldolases: an evolutionary history. Trends Biochem Sci. 1992;17(3):110-3.

59. Huber SC, Huber JL. Role and regulation of sucrose-phosphate synthase in higher plants. Annu Rev Plant Phys. 1996;47:431-44.

60. Tristan C, Shahani N, Sedlak TW, Sawa A. The diverse functions of GAPDH: Views from different subcellular compartments. Cell Signal. 2011;23(2):317-23.

61. Nielsen $\mathrm{TH}$, Rung JH, Villadsen D. Fructose-2,6-bisphosphate: a traffic signal in plant metabolism. Trends Plant Sci. 2004;9(11):556-63.

62. Tovar-Méndez A, Miernyk JA, Randall DD. Regulation of pyruvate dehydrogenase complex activity in plant cells. Eur J Biochem. 2003;270(6):1043-9.

63. Nakajima K, Furutani I, Tachimoto H, Matsubara H, Hashimoto T. SPIRALI encodes a plant-specific microtubule-localized protein required for directional control of rapidly expanding Arabidopsis cells. Plant Cell. 2004; 16(5):1178-90.

64. Palma JM, Sandalio LM, Corpas FJ, Romero-Puertas MC, McCarthy I, del Río LA. Plant proteases, protein degradation, and oxidative stress: role of peroxisomes. Plant Physiol Biochem. 2002;40(6-8):521-30. 
65. Li YR, Kabbage M, Liu WD, Dickman MB. Aspartyl protease-mediated cleavage of BAG6 is necessary for autophagy and fungal resistance in plants. Plant Cell. 2016;28(1):233-47.

66. Kasprzewska A. Plant chitinases - regulation and function. Cell Mol Biol Lett. 2003;8(3):809-24.

67. Ishiguro S, Kawai-Oda A, Ueda J, Nishida I, Okada K. The DEFECTIVE IN ANTHER DEHISCENCE1 gene encodes a novel phospholipase A1 catalyzing the initial step of jasmonic acid biosynthesis, which synchronizes pollen maturation, anther dehiscence, and flower opening in Arabidopsis. Plant Cell. 2001;13(10):2191-209.

68. van Damme M, Huibers RP, Elberse J, van den Ackerveken G. Arabidopsis DMR6 encodes a putative 20G-Fe (II) oxygenase that is defense-associated but required for susceptibility to downy mildew. Plant J. 2008;54(5):785-93.

69. Schillinger WF, Donaldson E, Allan RE, Jones SS. Winter wheat seedling emergence from deep sowing depths. Agron J. 1998;90(5):582-6.

70. Richards RA. The effect of dwarfing genes in spring wheat in dry environments. I. Agronomic characteristics. Aust J Agr Res. 1992:43(3):517-27.

71. Butler JD, Byrne PF, Mohammadi V, Chapman PL, Haley SD. Agronomic performance of Rht alleles in a spring wheat population across a range of moisture levels. Crop Sci. 2005;45(3):939.

72. Zhang J, Gizaw SA, Bossolini E, Hegarty J, Howell T, Carter AH, Akhunov E, Dubcovsky J. Identification and validation of QTL for grain yield and plant water status under contrasting water treatments in fall-sown spring wheats. Theor Appl Genet. in press.

73. Gooding MJ, Uppal RK, Addisu M, Harris KD, Uauy C, Simmonds JR, Murdoch AJ. Reduced height alleles (Rht) and Hagberg falling number of wheat. J Cereal Sci. 2012;55(3):305-11.

74. van de Velde K, Chandler PM, van der Straeten D, Rohde A. Differential coupling of gibberellin responses by Rht-B1C suppressor alleles and Rht-B1b in wheat highlights a unique role for the DELLA N-terminus in dormancy. J Exp Bot. 2017;68(3):443-55

75. Wojciechowski T, Gooding MJ, Ramsay L, Gregory PJ. The effects of dwarfing genes on seedling root growth of wheat. J Exp Bot. 2009;60(9):2565-73.

76. McCaig TN, Morgan JA. Root and shoot dry matter partitioning in nearisogenic sheat lines differing in height. Can J Plant Sci. 1993;73(3):679-89.

77. Youssefian S, Kirby EJM, Gale MD. Pleiotropic effects of the GA-insensitive Rht dwarfing genes in wheat. 1. Effects on development of the ear, stem and leaves. Field Crops Res. 1992:28(3):179-90.

78. Willige BC, Ghosh S, Nill C, Zourelidou M, Dohmann EMN, Maier A, Schwechheimer C. The DELLA domain of GA INSENSITIVE mediates the interaction with the GA INSENSITIVE DWARF1A gibberellin receptor of Arabidopsis. Plant Cell. 2007;19(4):1209-20.

79. Wu J, Kong X, Wan J, Liu X, Zhang X, Guo X, Zhou R, Zhao G, Jing R, Fu X, Jia J. Dominant and pleiotropic effects of a GAl gene in wheat results from a lack of interaction between DELLA and GID1. Plant Physiol. 2011;157(4): 2120-30.

80. Lou XY, Li X, Li AX, Pu MY, Shoaib M, Liu DC, Sun JZ, Zhang AM, Yang WL. Molecular characterization of three GIBBERELLIN-INSENSITIVE DWARF2 homologous genes in common wheat. PLoS One. 2016;11(6):e0157642.

81. Locascio A, Blázquez MA, Alabadí D. Genomic analysis of DELLA protein activity. Plant Cell Physiol. 2013;54(8):1229-37.

82. Claeys H, De Bodt S, Inzé D. Gibberellins and DELLAs: central nodes in growth regulatory networks. Trends Plant Sci. 2014;19(4):231-9.

83. Sun TP. The molecular mechanism and evolution of the GA-GID1-DELLA signaling module in plants. Curr Biol. 2011;21(9):R338-45.

84. Ubeda-Tomás S, Swarup R, Coates J, Swarup K, Laplaze L, Beemster GTS, Hedden P, Bhalerao R, Bennett MJ. Root growth in Arabidopsis requires gibberellin/DELLA signalling in the endodermis. Nat Cell Biol. 2008;10(5):625-8.

85. Achard P, Gusti A, Cheminant S, Alioua M, Dhondt S, Coppens F, Beemster GTS, Genschik P. Gibberellin signaling controls cell proliferation rate in Arabidopsis. Curr Biol. 2009;19(14):1188-93.

86. Gonzalez N, de Bodt S, Sulpice R, Jikumaru Y, Chae E, Dhondt S, van Daele T, de Milde L, Weigel D, Kamiya Y, Stitt M, Beemster GTS, Inze D. Increased leaf size: different means to an end. Plant Physiol. 2010;153(3):1261-79.

87. Iqbal N, Nazar R, Khan MIR, Masood A, Khan NA. Role of gibberellins in regulation of source-sink relations under optimal and limiting environmental conditions. Curr Sci. 2011;100(7):998-1007.

88. Ribeiro DM, Araújo WL, Fernie AR, Schippers JHM, Mueller-Roeber B. Action of gibberellins on growth and metabolism of Arabidopsis plants associated with high concentration of carbon dioxide. Plant Physiol. 2012;160(4):1781-94
89. Flechner A, Gross W, Martin WF, Schnarrenberger C. Chloroplast class I and class II aldolases are bifunctional for fructose-1,6-biphosphate and sedoheptulose-1,7-biphosphate cleavage in the Calvin cycle. Febs Lett. 1999:447(2-3):200-2.

90. Uematsu K, Suzuki N, Iwamae T, Inui M, Yukawa H. Increased fructose 1,6bisphosphate aldolase in plastids enhances growth and photosynthesis of tobacco plants. J Exp Bot. 2012;63(8):3001-9.

91. Cai B, Li Q, Liu F, Bi H, Ai X. Decreasing fructose 1,6-bisphosphate aldolase activity reduces plant growth and tolerance to chilling stress in tomato seedlings. Physiol Plant. 2017. https://doi.org/10.1111/ppl.12682.

92. Ishimaru K, Ono K, Kashiwagi T. Identification of a new gene controlling plant height in rice using the candidate-gene strategy. Planta. 2004;218(3):388-95.

93. Park AY, Canam T, Kang KY, Ellis DD, Mansfield SD. Over-expression of an arabidopsis family A sucrose phosphate synthase (SPS) gene alters plant growth and fibre development. Transgenic Res. 2008;17(2):181-92.

94. Davière JM, Achard P. A pivotal role of DELLAs in regulating multiple hormone signals. Mol Plant. 2016;9(1):10-20.

95. Oh E, Zhu JY, Bai MY, Arenhart RA, Sun Y, Wang ZY. Cell elongation is regulated through a central circuit of interacting transcription factors in the Arabidopsis hypocotyl. Elife. 2014;3:e03031.

96. Shan QW, Wang YP, Li J, Gao CX. Genome editing in rice and wheat using the CRISPR/Cas system. Nat Protoc. 2014:9(10):2395-410.

97. Zhang Y, Liang Z, Zong Y, Wang YP, Liu JX, Chen KL, Qiu JL, Gao CX. Efficient and transgene-free genome editing in wheat through transient expression of CRISPR/Cas9 DNA or RNA. Nat Commun. 2016;7:12617.

98. Rohland N, Reich D. Cost-effective, high-throughput DNA sequencing libraries for multiplexed target capture. Genome Res. 2012;22(5):939-46.

99. Zadoks JC, Chang TT, Konzak CF. A decimal code for the growth stages of cereals. Weed Res. 1974;14:415-21.

100. Pearce S, Kippes N, Chen A, Debernardi JM, Dubcovsky J. RNA-seq studies using wheat PHYTOCHROME B and PHYTOCHROME C mutants reveal shared and specific functions in the regulation of flowering and shade-avoidance pathways. BMC Plant Biol. 2016;16(1):141.

101. Wu TD, Nacu S. Fast and SNP-tolerant detection of complex variants and splicing in short reads. Bioinformatics. 2010;26(7):873-81.

102. Anders S, Pyl PT, Huber W. HTSeq-a Python framework to work with highthroughput sequencing data. Bioinformatics. 2015;31(2):166-9.

103. Love MI, Huber W, Anders S. Moderated estimation of fold change and dispersion for RNA-seq data with DESeq2. Genome Biol. 2014;15(12):550.

104. Robinson MD, McCarthy DJ, Smyth GK. edgeR: a Bioconductor package for differential expression analysis of digital gene expression data. Bioinformatics. 2010;26(1):139-40.

105. Benjamini $Y$, Hochberg $Y$. Controlling the false discovery rate: a practical and powerful approach to multiple testing. J Roy Stat Soc B Met. 1995;57(1):289-300.

106. Lex A, Gehlenborg N, Strobelt H, Vuillemot R, Pfister H. UpSet: visualization of intersecting sets. leee T Vis Comput Gr. 2014;20(12):1983-92.

107. Conway JR, Lex A, Gehlenborg N. UpSetR: an R package for the visualization of intersecting sets and their properties. Bioinformatics. 2017;33(18):2938-40.

\section{Ready to submit your research? Choose BMC and benefit from:}

- fast, convenient online submission

- thorough peer review by experienced researchers in your field

- rapid publication on acceptance

- support for research data, including large and complex data types

- gold Open Access which fosters wider collaboration and increased citations

- maximum visibility for your research: over $100 \mathrm{M}$ website views per year

At $\mathrm{BMC}$, research is always in progress.

Learn more biomedcentral.com/submissions 